\title{
The Trajectory of Coping with Trauma: Meaning Making as a Factor in Determining the Trauma Outcome for Combat Veterans
}

Rachel A. Spero

Follow this and additional works at: https://researchrepository.wvu.edu/etd

\section{Recommended Citation}

Spero, Rachel A., "The Trajectory of Coping with Trauma: Meaning Making as a Factor in Determining the Trauma Outcome for Combat Veterans" (2016). Graduate Theses, Dissertations, and Problem Reports. 6702.

https://researchrepository.wvu.edu/etd/6702

This Dissertation is protected by copyright and/or related rights. It has been brought to you by the The Research Repository @ WVU with permission from the rights-holder(s). You are free to use this Dissertation in any way that is permitted by the copyright and related rights legislation that applies to your use. For other uses you must obtain permission from the rights-holder(s) directly, unless additional rights are indicated by a Creative Commons license in the record and/ or on the work itself. This Dissertation has been accepted for inclusion in WVU Graduate Theses, Dissertations, and Problem Reports collection by an authorized administrator of The Research Repository @ WVU.

For more information, please contact researchrepository@mail.wvu.edu. 
The Trajectory of Coping with Trauma: Meaning Making as a Factor in Determining the Trauma Outcome for Combat Veterans

Rachel A. Spero, M.S.

Dissertation submitted to the College of Education and Human Services at West Virginia University in Partial Fulfillment of the Requirements

for the Degree of

Doctor of Philosophy in

Counseling Psychology

Jennifer Taylor, Ph.D., Chair

James Bartee, Ph.D.

Jeffrey Daniels, Ph.D.

Christa Lilly, Ph.D.

Christine Schimmel, Ed.D.

Department of Counseling, Rehabilitation Counseling, and Counseling Psychology

$$
\text { Morgantown, WV }
$$

2015

Keywords: PTSD, resilience, PTG, meaning-making, trauma, veterans, combat Copyright 2015 Rachel A. Spero 


\section{ABSTRACT \\ The Trajectory of Coping with Trauma: Meaning Making as a Factor in Determining the Trauma Outcome for Combat Veterans}

\section{Rachel A. Spero, M.S.}

Specific ways in which an individual makes meaning following a stressful life event have been conceptualized as contributing to the emergence of Posttraumatic Stress Disorder (PTSD).

However, little is known about how meaning making impacts the trauma trajectory and how that transition affects the outcomes of PTSD, Posttraumatic Growth (PTG), or resiliency. In this study, 166 combat veterans nationwide completed self-report surveys that were analyzed using a multivariate Structural Equation Modeling (SEM) method to create a model of how PTSD, PTG, and resiliency are impacted based upon meaning making. The results suggest that following a stressful life event, individuals who maintain intact world beliefs are more likely to be resilient. Individuals who experience a shattering of their world beliefs are hypothesized to report symptoms of PTSD. Likewise, individuals who experience a shattering of world beliefs and engage in avoidance coping are more likely to experience PTSD. However, individuals who experience a shattering of world beliefs but then make meaning from their experience are more likely to report an experience of PTG. Limitations and future directions of this research are also discussed in relation to the field's movement toward outlining factors that positively impact PTG following deployment. 


\section{TABLE OF CONTENTS}

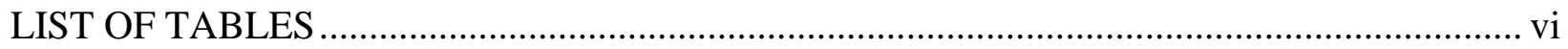

LIST OF FIGURES ............................................................................................... vii

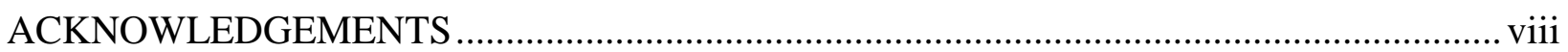

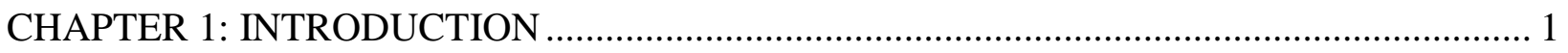

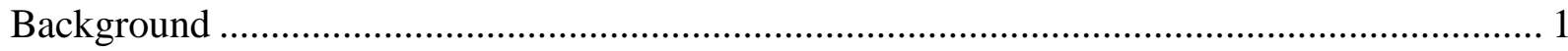

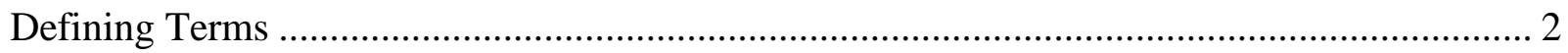

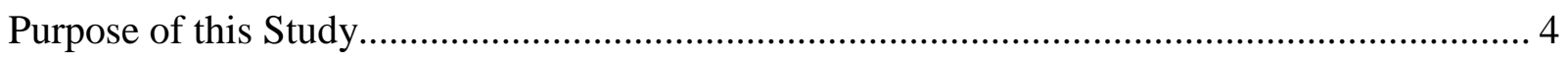

CHAPTER 2: REVIEW OF SELECTED LITERATURE .................................................... 5

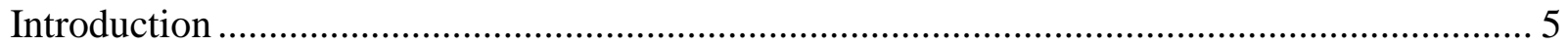

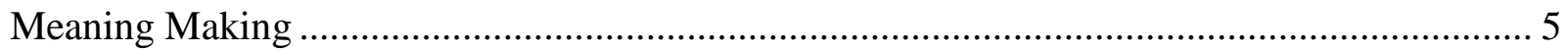

Posttraumatic Stress Disorder (PTSD) ..................................................................... 11

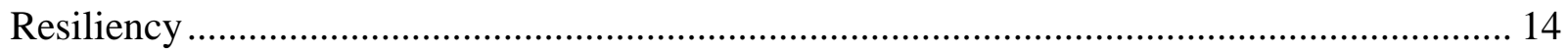

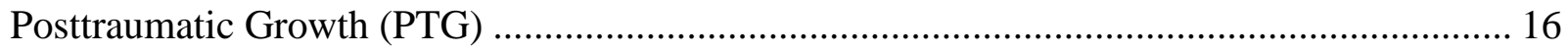

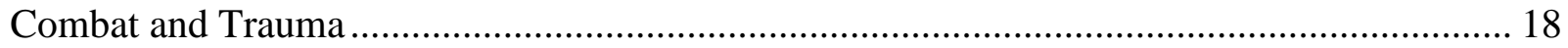

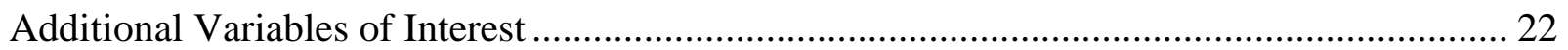

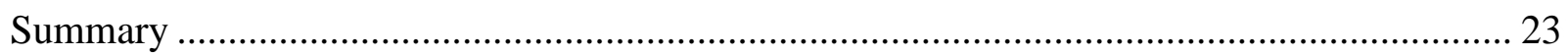

CHAPTER 3: RESEARCH DESIGN AND METHODOLOGY ........................................... 25

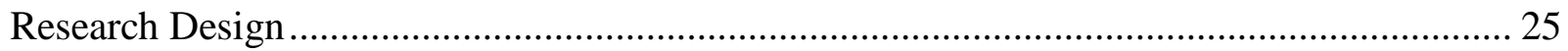

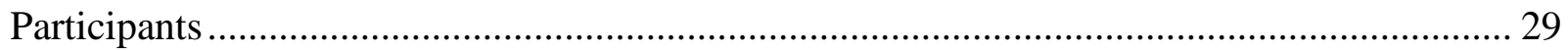




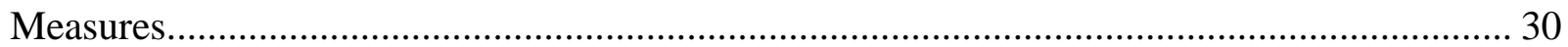

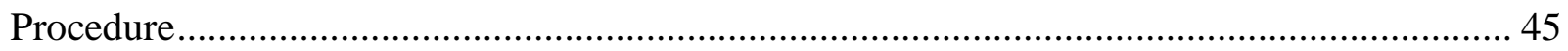

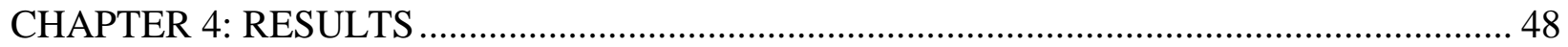

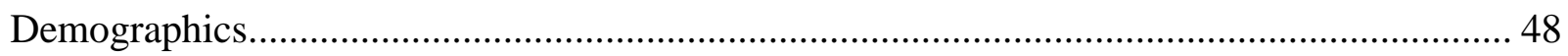

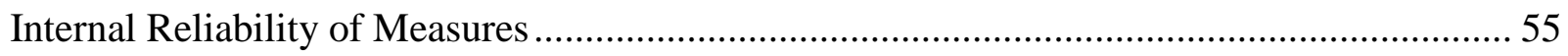

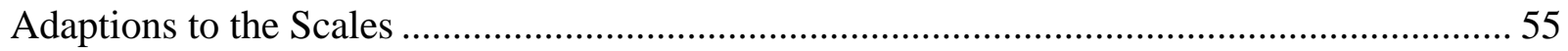

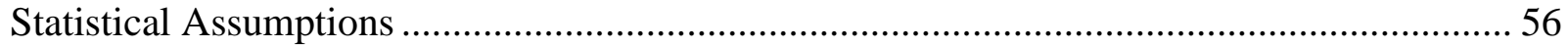

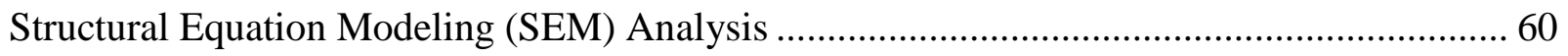

CHAPTER 5: INTERPRETATIONS, CONCLUSIONS, AND RECOMMENDATIONS........ 71

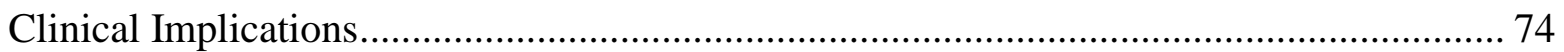

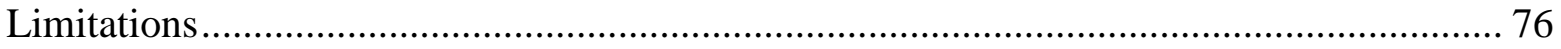

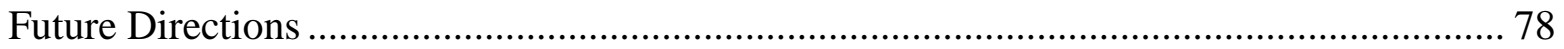

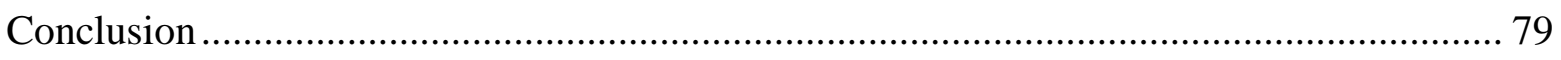

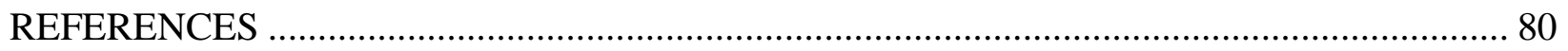

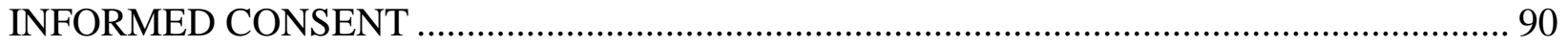

APPRAISED VIOLATIONS OF BELIEFS AND GOALS SCALE .................................... 92

THE WORLD ASSUMPTIONS SCALE ....................................................................... 93

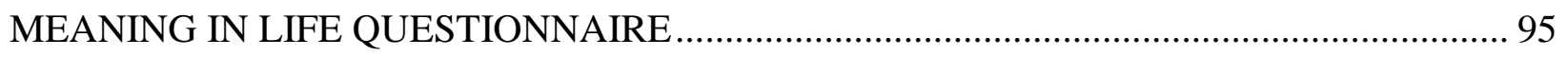

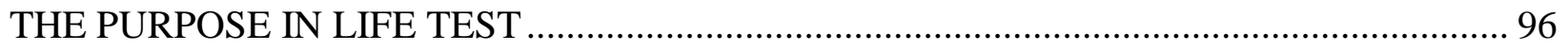

FINDING/FOUND MEANING QUESTIONS .......................................................... 99 
IMPACT OF EVENTS SCALE- REVISED .............................................................. 100

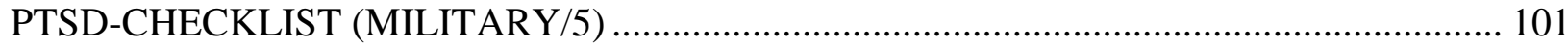

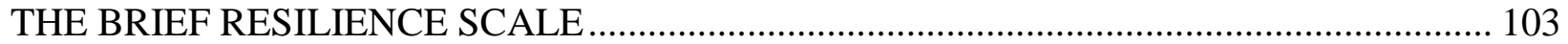

POSTTRAUMATIC GROWTH INVENTORY ............................................................ 104

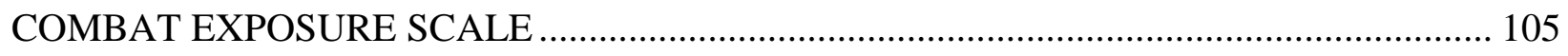

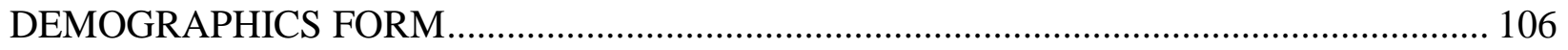




\section{LIST OF TABLES}

PAGE

Table 1. Cronbach's Alpha Scores for Measures.......................................40

Table 2. Demographics of Participants.............................................5

Table 3. Descriptive Statistics and Spearman Correlations between Demographic Variables

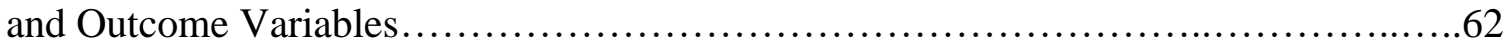

Table 4. Correlation Matrix for Variables Included Within the Model...........................66

Table 5. Fit Indices of the Models................................................. 70

Table 6. Fit Indices of the Model with the Inclusion of Demographic Variables as a Covariate for the PTSD Outcome......................................................... 74

Table 7. Fit Indices of the Model with the Inclusion of Demographic Variables as a Covariate for the Posttraumatic Growth Outcome............................................ 75

Table 8. Fit Indices of the Model with the Inclusion of Demographic Variables as a Covariate for the Resiliency Outcome....................................................... 76 


\section{LIST OF FIGURES}

PAGE

Figure 1. Park's (2008) Proposed Meaning Making Model...............................17

Figure 2. Larner and Blow's (2011) Proposed Meaning Making Model for Veterans...........28

Figure 3. The Proposed Meaning Making Model/Trajectory for Veterans for this Study........36

Figure 4. Hypothesized Model (After Correct Model Specification).......................69

Figure 5. Hypothesized Model with Standardized Beta Paths..............................70

Figure 6. Direct Effects of Variables............................................ 72

Figure 7. Best Fitting Model with Standardized Beta Coefficient Estimates...................78 


\section{Acknowledgements}

First and foremost, I would like to thank all of the military members who have served our country. I am continuously inspired and grateful for the bravery and sacrifice that service members continuously make for our country. I would also like to express my extreme gratitude to my dissertation chair, Dr. Jennifer Taylor, and my statistics guru, Dr. Christa Lilly. Without both of these individuals' time, support, and vast knowledge; this dissertation would still be no more than just a concept. Additionally, I would like to specifically thank my other dissertation committee members: Dr. Jeff Daniels, Dr. Chris Schimmel, and Dr. James Bartee. Their dedication to supporting this study was without rival. My sincere gratitude is also owed to Dr. Joseph Scotti for his guidance though the IRB process and as an expert in the field of veteran issues. Finally, I would like to thank my parents. My mother and father have unequivocally supported me through my entire graduate career, and for that, I am forever grateful. 


\section{CHAPTER 1: INTRODUCTION}

\section{Background}

Since the terrorist attacks on September 11, 2001, over 1.6 million Americans have been deployed overseas and many of those military personnel have engaged in combat (Seal et al., 2010). This has caused an increased awareness, and an influx, of research into the area of wartime trauma and the difficulties related to readjustment into society post-deployment (Hoge et al., 2004). Much of the literature on trauma focuses on the trajectory of Posttraumatic Stress Disorder (PTSD) following a trauma or resiliency factors that affect the likelihood that someone who has experienced a trauma can overcome or "bounce back" from the event (e.g. Dickstein, Muvak, Litz, \& Adler, 2010; McLean et al., 2011). Variables that may be predictors for PTSD have been identified, such as individual demographics, pre-trauma functioning, characteristics of the event, and posttraumatic factors (Dickstein et al., 2010). However, meta-analyses have indicated that these factors account for less than $20 \%$ of the variability in the development of PTSD (Ozer, Best, Lipsey, \& Weiss, 2003). Additionally, the results of research on the factors related to resiliency have not been able to account for all the variability of posttraumatic outcomes (Davis, Wohl, \& Verberg, 2007).

While there is significant variability in posttraumatic outcomes following wartime trauma, many veterans also report positive outcomes from wartime experiences that are gained following initial periods of distress (Larner \& Blow, 2011). In an attempt to explain the positive outcomes of wartime stressors and in response to accounting for the unknown variability in posttraumatic trajectories, researchers have recently investigated the outcome of posttraumatic growth (PTG; Dickstein et al., 2010). With the addition of PTG to other potential outcomes of wartime trauma, including resiliency and PTSD, researchers are now better able to account for 
the variability of outcomes (Dickstein et al., 2010). This allows researchers to conceptualize a much broader view of the way in which pathology does or does not develop.

Some studies have analyzed common trajectories for those who experienced a stressful life event. Davis, Wohl, and Verberg (2007) used participants experiencing the loss of a loved one in a mining accident and grouped the degree of PTG into one of three categories: rebuilt self, minimal growth, and no growth. Dickstein and colleagues (2010) used four categories to group participants according to PTSD symptomology: delayed symptomology, unrealized anxiety, resiliency, and recovery. While these studies attempted to describe the trajectory of outcomes following a trauma event, their results did not converge into a cohesive model (Davis, Wohl, \& Verberg, 2007; Dickstein et al., 2010). Thus, the need remains for a cohesive model that maps the course of trauma, from the exposure to the incident to realized outcomes.

In this chapter, the theoretical and historical viewpoints that explain the multiple trauma trajectories are explained, as well as the differences between general traumatic experiences and combat related traumatic experiences. Additionally, a model of trauma trajectories that will be used to test these theories (Larner \& Blow, 2011) will be presented. Lastly, a specific trajectory path for combat related trauma, based on literature on other forms of trauma, is explored.

\section{Defining Terms}

Multiple definitions exist for the terms trauma, PTSD, resiliency, and PTG. For the purpose of this dissertation, the most widely used definitions will be used. Trauma, also discussed in the literature as "stress exposure" or "a potentially traumatic event," has been defined as an event in which an individual believes there are serious threats to his or her life or the life of a loved one (Davis, Wohl, \& Verberg, 2007; McLean et al., 2011; Park \& Ai, 2006). 
Trauma is subjective to the individual's interpretation of the event. An event that is considered to be traumatic by one individual may not be considered traumatic by another individual.

Thus, when an individual experiences trauma, the result may be PTSD. Post-Traumatic Stress Disorder has been defined by Larner and Blow (2011) in the literature as a "decline" or "pathology process" that "occurs when an individual is not able to cope with the trauma and develops a pathological response, often resulting in a diagnosable mental health condition" (p. 187). Some researchers consider the pathology process to include PTSD, depression, and suicidal ideation (Larner \& Blow, 2011). However, given the limited research on the trauma trajectory process for veterans, for the purpose of this study, the pathology process is limited to, and focused on, PTSD outcomes.

While the "pathology process" leads to PTSD, this process may not occur if a resiliency process occurs instead. Resilience, or resiliency, in terms of PTSD, is defined as exposure to events that others may consider traumatic without the development of PTSD or other pathological responses (Larner \& Blow, 2011). Those who are resilient typically are able to "bounce back" from stressful situations without much difficulty. Some definitions of resiliency include a period of personal growth following a stressful event (Linley \& Joseph, 2011). While this definition connects the constructs of PTG with resiliency, the literature suggests that the differentiating factor between PTG and resiliency is the individual's perception of a stressful event as a crisis or trauma and his or her level of difficulty in overcoming the event (Larner \& Blow, 2011). Because the prevailing literature distinguishes resiliency from PTG, these two constructs are explored in this study as separate entities.

While PTG is similar to PTSD, in that the individual initially experiences trauma-related difficulties, with PTG, the individual later experiences growth or positive change following the 
struggle with trauma (Tedeschi \& Calhoun, 2004). PTG outcomes generally include changed priorities, greater appreciation for the value of the individual's own life, a better understanding of spiritual matters or stronger religious faith, and the discovery of personal strength that was previously unrealized (Larner \& Blow, 2011). The concepts of resiliency and PTG are derived largely from positive psychology literature but also have roots in cognitive theory, health psychology, humanistic, and existential therapies (Park, 2010).

\section{Purpose of this Study}

Given the relevant research, it was hypothesized that trauma trajectory outcomes following a stressful combat experience can be mapped. Post-traumatic stress disorder, resiliency, and PTG were considered trauma outcomes. The factor that was hypothesized to determine the trauma trajectory is the meaning that the individual ascribes to the stressful situation and any meaning that may be ascribed to the event after it occurs. The topic of meaning is described in greater depth in the next chapter.

It was the goal of this study to employ a quantitative methodological approach to explore factors that are related to the variability in trauma outcomes. Utilizing Path Analysis, a step through statistical process was conducted to determine the structure of the relationship between the targeted variables. Upon determination that the data met the criteria for multivariate normality, a Structural Equation Modeling (SEM) process was then conducted to determine the strength of the relationships among the variables. This is discussed in greater detail within the following chapters. The overarching goal of this study was to empirically explore and advance the theoretical framework for PTSD, resiliency, and PTG outlined by Larner and Blow (2011). 


\section{CHAPTER 2: REVIEW OF SELECTED LITERATURE}

\section{Introduction}

In this chapter, the literature that surrounds the constructs of meaning making, Posttraumatic Stress Disorder (PTSD), resiliency, and Posttraumatic Growth (PTG) are discussed. The theoretical underpinnings as well as the history of research in each area are explored. Other factors that may influence PTSD, resiliency, and PTG are also discussed. The chapter concludes with a discussion of why combat trauma differs from other forms of trauma and a discussion of the combat trauma trajectory model that was examined in this study.

The model that this study is based upon is grounded in the theory that meaning making is the determining factor in the trajectory of the trauma outcome, and the literature in this chapter will be explored with this assumption in mind. Within this model, meaning making can occur at different stages. During the stressful event, the situation is given an appraised meaning by the individual. If the appraised meaning violates the individual's previously held world views, then he or she may or may not engage in meaning making to create consistency between his or her world view and the stressful event. This study explores how different meaning making outcomes are related to different trauma outcomes.

\section{Meaning Making}

The way that an individual constructs his or her world view has a far reaching effect on that individual's life and behavior. Researchers from Frankl to Rogers to Seligman have explored the way in which world views shape our lives. Previous research has documented types of world views such as a Just World Belief or a Belief in a Vengeful Higher Power (Kauffman, 2002). How these types of world views interact with our daily lives has become the focus of a substantial amount of the current literature (Kauffman, 2002). For example, psychologists 
contend that world views act as a basis for how individuals will see the world, such that they will try to fit daily occurrences into their world view and act in a congruent manner (Park, 2010). This phenomenon is similar to the theory that was initially explained by Heider in his motivation theory of attitude change called Balance Theory in which cognitive consistency and balance are the driving factors in trying to maintain one's values and beliefs across the lifetime (Heider, 1946).

Meaning making is a process that occurs at every moment of our lives (Janoff-Bulman, 1989). Individuals are constantly assessing situations and determining what significance the moment has on their lives. Most situations fit into already constructed categories of meaning (Janoff-Bulman, 1989). These categories create a collective world view that is unique to each individual. However, general types of world views have begun to be defined. A Just World Belief and a Belief in a Vengeful Higher Power are two of the most common world beliefs, although there are many others that have been postulated (Kauffman, 2002).

World views are constantly being challenged by events in the world. During an extremely stressful life event, Park (2011) stipulated that individuals will evaluate their world views in comparison to an appraised meaning of the event to determine if the two are discrepant. If no discrepancy occurs, the individual has successfully adjusted. However, if a discrepancy does occur, the individual will experience distress and will engage in the meaning making process. For example, an individual may hold the belief that some people can be trusted but others may not be trustworthy. If this person experiences a situation in which someone is not trustworthy, his or her internal belief system allows for this flexibility and no discrepancy occurs, thus successfully adjusting to this situation. However, if an individual experiences the prior situation 
but holds the belief that all people can be trusted, he or she is faced with a discrepancy between his/ her experience and the individual's belief and will likely need to rectify the discrepancy.

This process of cognitive change bears similarity to the cognitive dissonance model developed by Leon Festinger (1962). Cognitive dissonance is the presence of two or more incongruent cognitions or beliefs. The cognitive dissonance model postulates that the existence of cognitive dissonance is psychologically uncomfortable, and individuals will attempt to reduce the discomfort by achieving consonance (Festinger, 1962).

Park (2010) explained the cognitive dissonance process in relation to a traumatic event. Park described individuals in the meaning making process as those engaging in behaviors that are intended to reduce the perceived discrepancy between global and situational appraised meaning. This process involves both the automatic (unconscious) process of meaning making, as well as deliberate or mindful attempts at meaning making. Thus, this process is both cognitive and emotional. Individuals engaged in this process likely work toward assimilating appraised meaning to fit global meaning; or conversely, they work toward accommodating global beliefs to fit the appraised meaning. They are generally searching for the comprehensibility or significance of the event.

Reactions to traumatic experiences vary. When a stressor is considered traumatic, an individual may respond in two ways. The individual may be successful in the meaning making process and would then progress to PTG (Park, 2010). Conversely, an individual may be unsuccessful in finding meaning and would then experience greater stress and ultimately, PTSD.

Linley and Joseph (2011) stipulated that the process of changing a meaning system is stressful, but necessary, to develop the positive sense of meaning. In their research, Linley and Joseph (2011) found that following a traumatic event, individuals who found meaning in their 
lives had lower levels of stress, higher levels of cognitive and emotional growth and a sense of resilience; whereas individuals still searching for meaning experienced greater negative change. Park (2010) found that those who attempt to make meaning and are successful fare similarly, or better than, those who do not attempt to make meaning. On the other hand, individuals who attempt to make meaning, and are unable to find meanings, typically fare worse than those individuals who did not engage in any meaning making.

Davis, Wohl, and Verberg (2007) reported that in a longitudinal study of individuals experiencing a "senseless" loss of a loved one, those who were unable to find meaning at the six month post-loss mark were rarely able to find meaning later. Not having made meaning of the loss at 18 months post-loss was predictive of worse emotional adjustment than those who had made meaning. After extensive review, it appears that no studies have been designed to assess the optimal time in which meaning making should occur.

Larner and Blow (2011) summarize literature surrounding meaning making by stating that people will engage in the meaning making process due to their global beliefs being shattered by the appraised meaning of the traumatic situation. They further stipulated that all individuals who engage in the meaning making process will initially experience difficulty. Those who are able to create meaning are able to alleviate their feelings of ambiguity and confusion, and experience growth following the process (Larner \& Blow, 2011).

Meaning making is a private event that individuals may not be able to clearly express to those around them (Tripplett et al., 2011). Since meaning making cannot be directly observed, researchers have begun to determine methods that can adequately predict that the process of meaning making is occurring. The presence of rumination about the event has been found to be one such indicator that the meaning making process is present (Tripplett et al., 2011). Intrusive 
thoughts and deliberate thinking about the event have been used to measure the process of meaning making that leads to PTG, and have found support as a factor related to meaning making in life (Tripplett et al., 2011).

Due to the literature linking meaning making as a process that occurs after a stressful life event, researchers have begun attempts to map the influence of meaning making on the outcomes of PTSD, resiliency, and PTG. Park (2008) evaluated the current theories of meaning making, and created an integrated theoretical model to describe the process, see Figure 1.

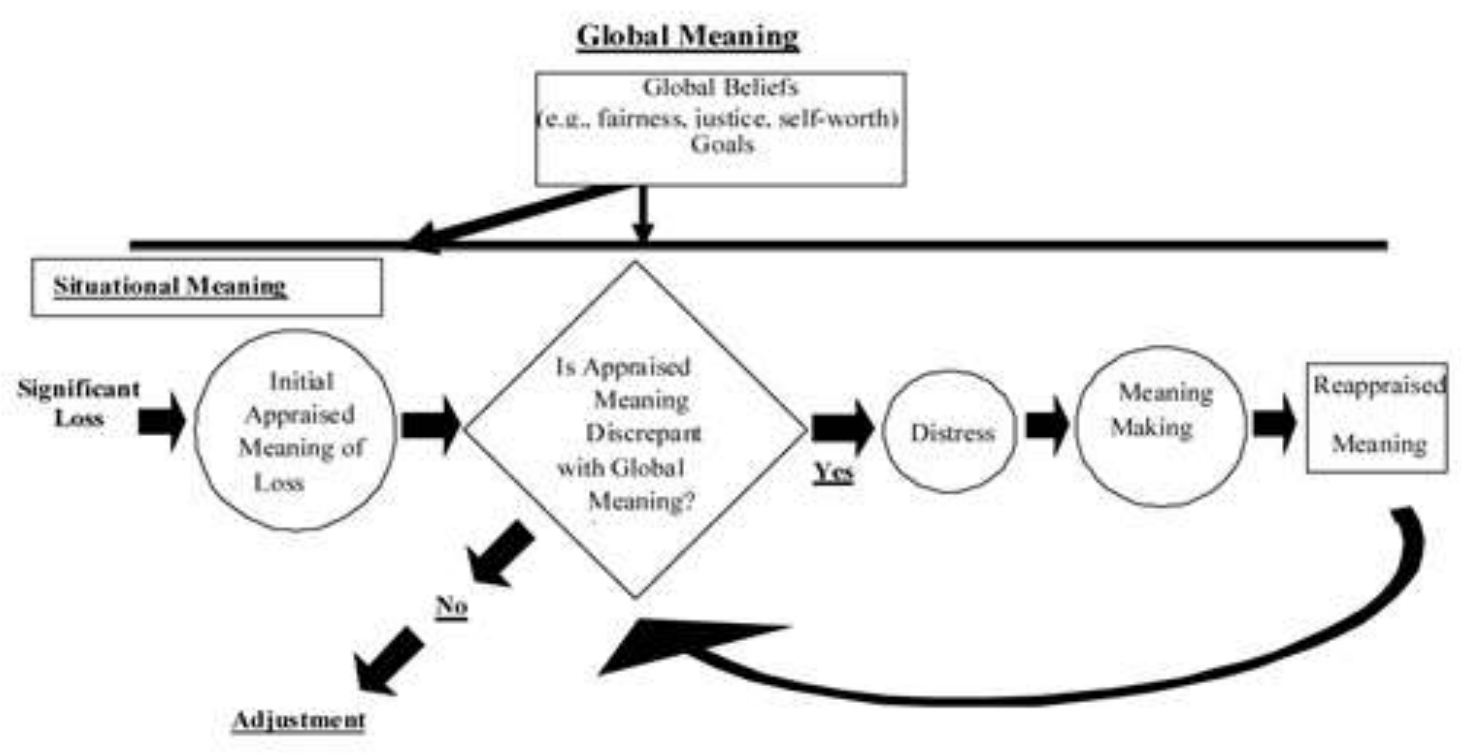

Figure 1. Park's (2008) proposed meaning-making model.

Park's (2008) model posits that individuals ascribe global meanings to life that include their broad views on justice, control, predictability, coherence, and self-views. Global meanings are similar to the construct of core beliefs in cognitive therapy, in that they reflect the individual's reactions to their experiences of the world. Individual global meaning can take the form of beliefs, goals, or a subjective sense of meaning or purpose. 
Similarly, Park's (2008) model also postulates that individuals will strive to create meaning with regard to specific stressful situations, sometimes termed situational meaning. Situational meaning is the meaning that is individually and subjectively derived from a particular event, or a stressful event as related to this topic. Situational meaning results in individual meaning event appraisal. In Cognitive Theory terms, the situational meaning or appraised event meaning is akin to automatic and/or intermediate thoughts. Aldwin (2007) described appraised event meaning as the individual's attempt to determine event threat level, controllability, the reason the event occurred, and its future impact on the individual.

Park's (2008) model suggests there are three trajectories that an individual can engage in following a stressful event. The trajectories defined by the model are: (1) no discrepancy between global meaning and situational meaning, leading to successful adjustment; (2) a successful meaning making attempt, also referred to as meaning made; or (3) unsuccessful in the meaning making process. In other research, the trajectories have been linked to psychological outcomes; specifically, trajectory one is linked to resiliency, trajectory two is linked to PTG, and trajectory three is linked to the pathology process or PTSD, respectively (Davis, Wohl, \& Verberg, 2007; Dickstein et al., 2010; Larner \& Blow, 2011).

Meaning making is a process that has been linked to PTSD, resiliency, and PTG. An emerging model in the literature focuses on the process of meaning making as the key determining factor in adjustment to stressful life events (Park \& Folkman, Larner \& Blow, 2011). Although meaning making attempts following a highly stressful event have been well documented and associated with PTSD, resiliency, and PTG individually (Park, 2010), no study to date has empirically examined meaning making as the determining factor in the trauma trajectory outcome. The next sections discuss meaning making as it is specifically related to the 
trauma outcomes of PTSD, resiliency, and PTG. The chapter concludes with a proposed study that examines all of these variables in one cohesive model.

\section{Posttraumatic Stress Disorder (PTSD)}

While the terms trauma, PTSD, resiliency, and PTG have already been defined, to understand the direction in which this field is headed, it is also important to explore the past with regard to the PTSD literature. Written accounts of symptoms closely resembling PTSD have been identified as far back as 1597 from the soliloquy of Lady Percy in Henry IV (Shay, 1994). The history of PTSD has most commonly been observed in military members returning from war. In the early part of the $19^{\text {th }}$ century, military medical doctors began to diagnose soldiers returning from combat with "exhaustion". Military members were expected to maintain a countenance of bravery and avoid showing fear during World War I. After exposure to multiple intense stressful situations, military medical doctors found an increasing number of soldiers who experienced fatigue as a natural physiological shock response (Parrish, 2008). A very common reaction to the fatigue experienced in combat was the shutdown of mental processes. Prior to the coining of the term PTSD, other terms used to express a similar set of symptoms included: stress syndrome, railway spine, shell shock, battle fatigue, post-Vietnam syndrome, and traumatic war neurosis (Andreasen, 2004).

The posttraumatic symptom cluster was dubbed "PTSD" in the mid-1970s. PTSD was explored as a potential diagnosable condition prior to the publication of the third edition of the Diagnostic and Statistical Manual of Mental Disorders (DSM-III) in 1978. The diagnosis of PTSD was officially included as a diagnosable disorder in the DSM-III in 1980 (American Psychiatric Association, 1980). Throughout the revisions of the DSM, PTSD has become the official term used to categorize individuals who have experienced a stressful life situation with 
symptoms persisting for a month or more after the trauma. Symptoms include flashbacks, bad dreams or nightmares, emotional numbness, intense guilt or worry, angry outbursts, feeling "on edge," and avoiding thoughts and situations that remind them of the trauma (DSM-IV-TR, American Psychiatric Association, 2000). With the publication of the DSM-5 in 2013, the diagnostic category for PTSD has again been expanded. The current criteria for diagnosis now include experiencing a stressor and meeting specific requirements in the categories of intrusion, avoidance, negative alterations in cognition or mood, and alterations in arousal and reactivity (DSM-5, American Psychiatric Association, 2013, p. 271-280).

Much progress has been made in understanding PTSD since the official addition of the term to the DSM in the early 1980s. The fourth edition of the DSM labeled PTSD as an anxiety disorder (DSM-IV-TR, American Psychiatric Association, 2000). With the publication of the fifth edition of the DSM, PTSD is now classified in the Trauma- and Stressor-Related Disorders section of the manual (American Psychiatric Association, 2013).

According to the DSM-5, the projected lifetime risk for having PTSD in the general public is $8.7 \%$ with the 12 -month prevalence among adults of about $3.5 \%$ (American Psychiatric Association, 2013). Rates of PTSD are higher among military service members who have been exposed to serious traumatic events, such as combat exposure. It is also more likely in younger adults than older adults (American Psychiatric Association, 2013). The DSM-5 also lists the risk and prognostic factors related to PTSD. Of the risk factors, lower socioeconomic status, lower education, family dysfunction, prior mental disorders, childhood adversity, cultural characteristics, lower intelligence, lower social support, gender, age, severity of the trauma, personal injury, negative appraisals, inappropriate coping strategies, and subsequent exposure to traumatic events are listed (American Psychiatric Association, 2013). The DSM-5 also lists 
social supports as a protective factor against the development of the disorder post-trauma (American Psychiatric Association, 2013). Individuals with protective factors tend to develop PTSD less often or less severely than those who do not have similar characteristics (Folkman, 1997). These risk and protective factors are discussed later in this section as potential variables of interest for the current study.

Janoff-Bulman (1989) found that when individuals experience a traumatic event, their world views can be shattered. It is believed that PTSD occurs when individuals get "stuck" trying to cope with and make meaning from these shattered world views (Resick, Monson, \& Chard, 2007). This idea is so prevalent that a specific evidence-based treatment has been created that focuses in on aiding clients to work through this problem. Cognitive Processing Therapy for veterans, created by Resick, Monson, and Chard (2007), focuses on the range of emotions that occur following a traumatic experience. The treatment allows clients to sort through their emotions and attempt to see how the event changed their life and to create a new meaning from the event (Resick et al., 2007).

PTSD is a clinical diagnosis that can affect an individual's life long after the stressful event ends. Within the Veteran's Administration alone, disability compensation for PTSD accounts for over $\$ 4.3$ billion (Tanielian, 2009). In a study by the Rand Corporation, it was estimated that the economic impact of veterans with PTSD costs the U.S. government and tax payers approximately four to six billion dollars every two years (Tanielian, 2009). It is likely that since that time, the cost of veteran care has only increased as more service members continue to serve in war-torn areas. Due to PTSD's large impact on society, researchers are beginning to focus on ways to prevent the emergence of PTSD in high-risk populations, especially military members entering into combat. 
It is believed that following a stressful event, such as a combat experience, individuals who initially experience a shattering of their world views and actively avoid any reminders of the trauma tend to experience PTSD. Avoidance of any reminders of the traumatic experience would indicate that the individual is not actively working to make meaning of the event and therefore has not created a cohesive meaning of the trauma. This concept is explored within this study by evaluating if, following a stressful life event, individuals who reported a higher level of the latent variable violation of world beliefs as well as a lower level of meaning and coping, also reported a higher level of PTSD.

Although meaning making appears to be a promising angle to study the prevention of PTSD, much of the preventative literature on PTSD focuses on increasing the resiliency of those entering into a combat situation (Seligman, 2012). In the next section, resiliency is explored as it relates to trauma and meaning making.

\section{Resiliency}

The term resilience was initially coined in the early 1970s as a way to describe why some individuals did not develop schizophrenia even in the presence of all major risk factors (Garmezy, 1973). Research on resilience quickly expanded in the 1980s to examine the success of children who grew up in chaotic families (Werner, 1971). Resilience is a construct that is viewed as more of a process and less of a trait. However, the term resiliency is also used to delineate the traits that people may possess that will enable them to become resilient (Masten, 1994). According to Masten (1994), results from research at the time suggested that individuals who exhibit resilience are more able to successfully interact with their environment. They are engaged in activities that either promote well-being or protect them from risk factors. Individuals considered resilient tend to utilize positive coping strategies and have influential figures in their 
lives that help to support them in times of high stress (Masten, 1994). Therefore, resilience is considered to occur when the cumulative protective factors outweigh the risk factors for a negative outcome (Masten, 1994). However, resilience in itself does not protect the individual from the experience of negative outcomes; resilience is believed to only reduce the impact of the negative event (Seligman, 2012).

Since the emergence of resilience in the psychological literature, researchers from many different theoretical camps have studied the construct. However, the construct of resiliency has garnered much attention from positive psychology researchers. Similar to other theories, positive psychology conceptualizes resilience as the ability for an individual to bounce back after a difficult life event (Seligman, 2012). Researchers found specific characteristics linked to resiliency, including emotional awareness or regulation, impulse control, optimism, empathy, self-efficacy, and the ability to reach out to others (Reivich, 2003). In his research with the Comprehensive Soldier Fitness Program through the United States Military, Seligman (2012) created a program that aimed to increase the resiliency of military troops. His curriculum includes training in the areas of strength, emotional, social, spiritual, and family. Individuals who have completed the Comprehensive Soldier Fitness Program report enjoying the program and report decreased levels of depression, suicidality, and PTSD when compared to those in the general military population (Seligman, 2012). However, there is a great need for more research to determine the stability and long-term efficacy of this program.

\section{Resiliency and Meaning Making}

Resiliency has also been measured through the lens of meaning making. It has been hypothesized that those who have a world view that allows for negative events to occur may be more resilient (Janoff-Bulman, 1989). For example, if an individual has a world view that the 
world is unpredictable and bad things can happen to anyone, it would be hypothesized that the individual would fare much better than an individual who had a more rigid belief about the world being a just and fair place. This concept is explored within this study by evaluating if, following a stressful life event individuals who reported lower violations of world beliefs also reported higher levels of resiliency.

Resiliency is a construct that has been defined and studied in many different ways. Although resiliency has been clearly defined as a process rather than a trait, many of the variables that increase the likelihood of an individual being resilient do not paint a clear path as to how resiliency actually occurs. Conceptualizing resiliency as a construct that is determined based upon an individual's world views is a parsimonious way to explain how and why resiliency occurs. It is hypothesized that resiliency can be predicted from meaning making. This study also aimed to clearly delineate the differences between resiliency and PTG through differences in the expression of meaning making. Posttraumatic Growth is a concept that is closely linked with resiliency and is explored in more detail.

\section{Posttraumatic Growth (PTG)}

The idea that individuals change or grow following a stressful life event is not a novel concept. Researchers were not the first to identify this phenomenon. The knowledge that an individual can change in very positive ways following difficulties is "ancient and widespread" (Calhoun \& Tedeschi, 2006, p. 3). The social sciences have begun to systematically study these events to determine the root of the positive changes that may occur following a traumatic event. In the past 15 to 20 years, researchers have begun to look at this human phenomenon from an empirical standpoint. The pioneers in the field of PTG are multidisciplinary, including researchers in psychology, social work, psychiatry, and counseling. 
Building on the multidisciplinary research in the field, current studies suggest that following a traumatic or stressful life event, individuals tend to experience changes in their perceptions. These may include changes in self-perception, changes in how they view those around them, or changes in their view on life (Calhoun \& Tedeschi, 2006). In recent research, a five-factor approach for the outcomes of PTG has been defined. The factors include personal strength, new possibilities, relating to others, appreciation of life, and spiritual change (Tedeschi \& Calhoun, 1996). Calhoun and Tedeschi (2006) have summarized the phenomenon of PTG by the phrase "vulnerable yet stronger" (Tedeschi \& Calhoun, 1996, p. 11).

In some PTG research, the level of PTG has also been associated with increased cognitive activity (Linley \& Joseph, 2004). Furthermore, the level of PTG has been positively associated with the degree of rumination related to the stressful event (Linley \& Joseph, 2004). Individuals are more likely to experience PTG when they view a stressful event as highly disruptive to themselves, resulting in a disruption of their personal narrative and increased rumination (Linley \& Joseph, 2004). These results suggest that PTG is a result of an individual engaging in active meaning making.

It is important to note that there are clear distinctions between the concepts of PTG and resilience. In resiliency, individuals are able to view the current stressful event in the context of other life events and put their stressful event in perspective better than those who are not resilient (Calhoun \& Tedeschi, 2006). Further, as previously noted, individuals who are considered resilient following a stressful life event possess world views that allow for the situation to make sense. This makes it unnecessary for the individuals to actively work to cognitively process the event. Although resilient individuals may experience negative emotions, they do not feel the need to create new views of themselves, the world, or the event (Calhoun \& Tedeschi, 2006). 
However individuals who experience PTG tend to work toward finding a level of comprehensibility and meaning from the event they experienced. They may experience high levels of stress and anxiety which are typically only relieved upon finding a sense of comprehensibility about the stressful life situation (Calhoun \& Tedeschi, 2006).

In summary, it is believed that following a stressful event, individuals who initially experience a shattering of their world views and actively work to create a new cohesive meaning will experience PTG. This concept is explored within this study by evaluating if, following a stressful life event, individuals who reported a higher level of the latent variable violation of world beliefs as well as a higher level of meaning and coping will be found to have also reported a higher level of PTG.

\section{Combat and Trauma}

While the constructs of PTSD, resiliency, and PTG have been explored, it is also important to explore the construct of combat-related trauma. It is necessary to note that the Park and Folkman (1997) model from which much of this discussion has been based upon, was created largely by using samples of individuals experiencing stressful life events due to the diagnosis and/or death of a loved one from a terminal disease. A few studies of women who had been assaulted were also included in their analysis. However, no trauma samples of veterans were used when developing the model. This leaves a gap in the literature for those who have suffered a trauma from a combat situation.

As Larner and Blow (2011) pointed out, combat trauma is different than experiencing a stressful life event and other types of trauma. Indeed, combat-related trauma is distinct from other forms of trauma, given differing levels of helplessness, controllability, expectations, experience of a life-threatening event, expectation of perpetrating trauma on others, and length of 
traumatic exposure. Post-9/11 service members voluntarily signed up for the military, many with the expectation of deployment. Entering into stressful situations is expected when deploying, which is quite different from an individual who does not expect to have a terminal medical diagnosis or an individual who is the victim of an assault (Larner \& Blow, 2011).

Military service members are trained in order to provide them with skills to help them persevere under stress, and they are then expected to do so. They may experience multiple traumas while in combat, which may include being shot at, witnessing their fellow service members injured or killed, shooting at others, and/or witnessing other atrocities of war. These experiences can occur over brief or extended periods of time during deployment, with alternating periods of extreme stress and boredom. Furthermore, it is not uncommon for a soldier to experience multiple deployments during military service (Larner \& Blow, 2011). Thus, the model for general experiences of stressful life events may not adequately explain the outcomes for veterans in general and Operation Enduring Freedom/Operation Iraqi Freedom/Operation New Dawn (OEF/OIF/OND) veterans, specifically. Military service members are considered to be veterans of OEF/OIF/OND if they served in a combat zone in the US Military between 2001 and the current date at the time that this was written in early 2015.

In an article by Larner and Blow (2011), the authors modified the Park and Folkman (2008) model to create a model of meaning making in combat veterans. In giving their reasons for the creation of the model, Larner and Blow (2011) explained:

If a group of veterans can return home after having essentially the same experiences but with a wide range of outcomes between them, then it could be possible that the differences in their responses may have less to do with what happened and more to do with a number of individual characteristics such as personality, individually perceived 
unit cohesion, and physiological stress tolerance, and ultimately with how each veteran creates meaning to cope with the events. (p. 188)

The model attempts to explain the trajectories of this population following a stressful combatrelated event (see Figure 2).

A MODEL OF MEANING-MAKING COPING AND GROWTH IN COMBAT VETERANS

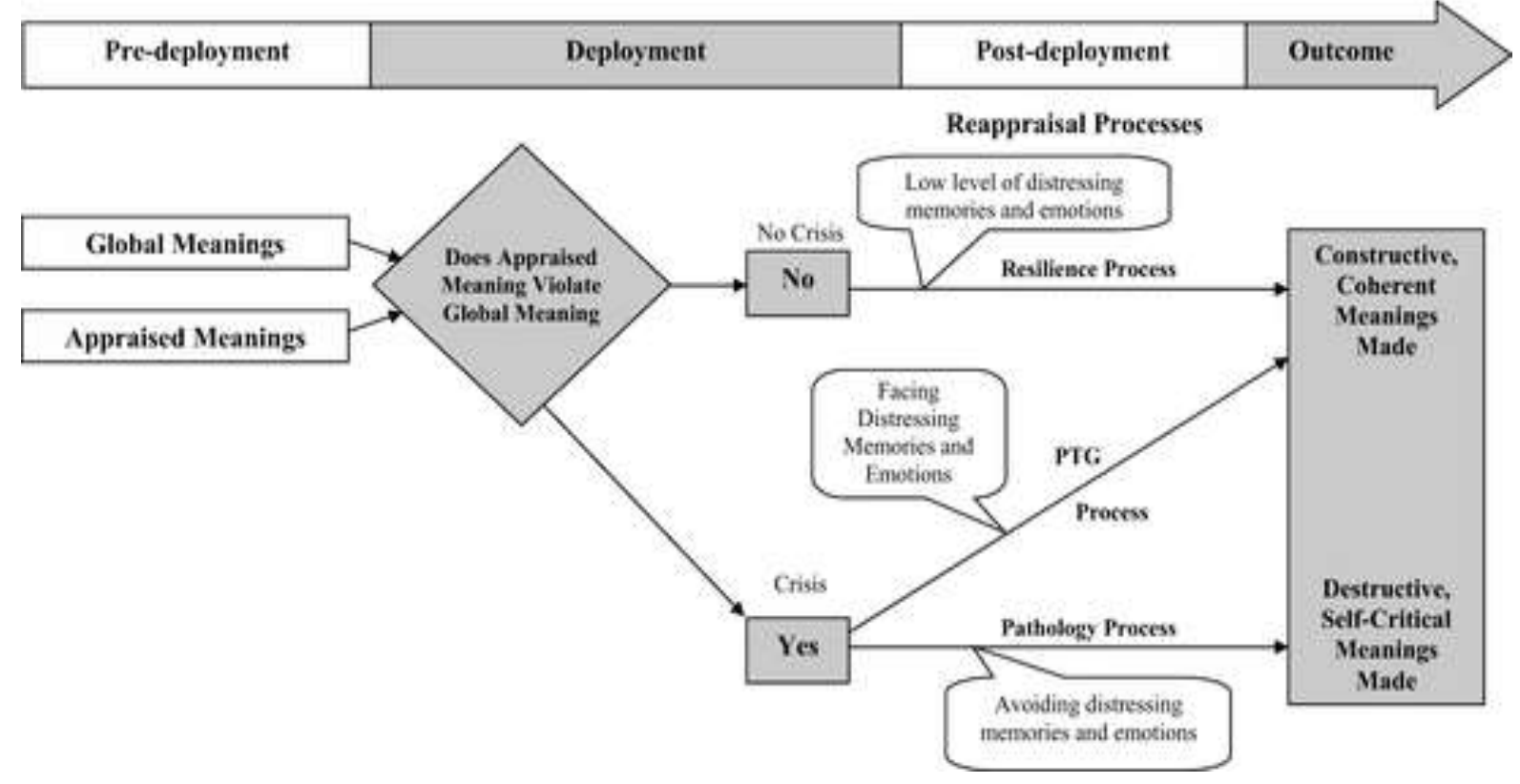

Figure 2. Larner and Blow's (2011) proposed meaning-making model for veterans.

The Larner and Blow (2011) model is similar to that of Park and Folkman (1997) in that it evaluates global meanings and appraised meanings for a violation or discrepancy. If no discrepancy is found, the individual does not experience a crisis, has low levels of distressing thoughts and feelings, and is considered to have engaged in the resilience process (Larner \& Blow, 2011). Similarly, if the individual does experience a discrepancy between his or her global meanings and appraised meanings, the individual will experience a crisis. However, Larner and Blow's (2011) model expands on Park and Folkman's (1997) model by indicating that the individual will then proceed toward either PTG or a "pathology process". As discussed, 
for the purpose of this study, the "pathology process" will be narrowed in focus to include only the construct of PTSD.

In the Larner and Blow (2011) model, individuals in the PTG process face their distressing memories and emotions during a reappraisal process, and this then leads to constructive, coherent meaning made. Alternatively, individuals in the PTSD or "pathology process" avoid the distressing memories and emotions during the reappraisal process and are left with either no meanings made or destructive, self-critical meanings made. The model describes a longitudinal aspect of the process; it moves across time starting with pre-deployment, deployment, post-deployment, and ends with the outcome of coherent meanings made or destructive, self-critical meanings made.

Building on Larner and Blow's (2011) hypothesized model, meaning making may have an important impact on the outcomes of PTSD, resilience, and PTG. The PTSD definition then becomes the "decline...indicative of a shattering of world assumptions with inadequate or failed attempts to cope" (Larner \& Blow, 2011, p. 187). Resiliency is then understood as "the ability of someone to experience trauma without a shattering of world assumptions, which in turn allows the individual to return to or surpass previous levels of functioning" (Larner \& Blow, 2011, p. 187). PTG can be further explained by the definition of "interpersonal growth or positive change resulting from struggling with trauma and growing in spite of it.... preceded by an initial shattering of world assumptions, a period of difficulty characterized, for example, by a PTSD diagnosis or severe PTSD-related symptoms, but followed by growth" (Larner \& Blow, 2011, p. 187).

When someone is able to move through the reappraisal process with low levels of distress (i.e., resilience process), it is believed that a prior global meaning existed and allowed the 
appraised meaning to fit seamlessly into their beliefs (Larner \& Blow, 2011; Park, 2010; Park \& $\mathrm{Ai}, 2006)$. If there is no meaning discrepancy, the individual may view the situation as stressful, but she or he will not experience a crisis or consider the event traumatic (Larner \& Blow, 2011; Park, 2010). For example, an individual who has the global belief that "bad things can happen to good people" would not experience a violation of global meaning if he or she experienced a stressful event and would not likely identify the event as a trauma.

On the other hand, an individual who has a "just world" global belief such that "the world is fair and just, good things happen to good people" (and the individual views himself or herself as a good person), will experience a violation of global meaning when experiencing a stressful event and considering the event a trauma. This individual will then need to engage in the reappraisal process. Similarly, the degree of discrepancy between the individual's appraised meaning and global meaning may be related to the degree of trauma experienced by the individual (Larner \& Blow, 2011).

The Larner and Blow (2011) model represents one incremental step toward the empirical exploration of meaning making following combat related trauma. In their model, meaning making has been linked to each specific trajectory independently. However, the model has not been tested cohesively, using meaning making as a predictive variable of PTSD, resiliency, and PTG. The goal of this study is to add empirical rigor to the existing trauma literature in an effort to move towards a cohesive model of PTSD, resiliency, and PTG among veterans.

\section{Additional Variables of Interest}

As previously mentioned, there are many risk and preventative factors for PTSD. Specifically, research suggests that females are at greater risk for the development of PTSD (Kline et al., 2013). Number of deployments has also been found to be risk factor for not only the 
development of PTSD but also for experiencing a traumatic event in general (Shen, Arkes, Kwan, Tan, \& Williams, 2010). Given the existing research, gender was considered a possible covariate in the prediction of PTSD and the number of deployments one experienced was considered a possible covariate in the prediction of PTSD, resiliency, and PTG.

Other variables may contribute to the degree of meaning making, PTSD, resiliency, and PTG but have not been directly linked to the process currently under examination. Included within the study's demographics form were individual factors that may increase or decrease a military member's likelihood to develop PTSD (Mott, Graham, \& Teng, 2012; Renshaw, 2010; Riviere, Kendall-Robbins, McGurk, Castro, A., \& Hoge, 2011). These factors are age, length of deployment, level of education, branch of the military, military grade, income level, level of selfperceived religiosity or spirituality, incidences of traumatic brain injuries, chronic pain resulting from combat injury, social supports, and receiving any mental health services upon returning from combat.

\section{Summary}

Meaning making, PTSD, resiliency, and PTG are all areas that have received considerable focus in the research literature. Only recently have these concepts begun to be examined together as potentially creating an intertwined story. It is possible that meaning making may be one of the determining factors in a trauma trajectory that leads to the outcomes of PTSD, resiliency, and PTG. Since these constructs have not been previously studied as a cohesive model, there is a gap in the literature that is partially filled by this study.

The goal of this study was to explore and build upon the trauma trajectory model proposed by Larner and Blow (2011). The proposed model hypothesized that not experiencing global meaning violation following a stressful combat experience predicts resiliency (no crisis); 
whereas experiencing global meaning violation predicts both PTSD and PTG. It was further hypothesized that successful attempts at meaning making predict PTG; whereas, unsuccessful attempts predict PTSD. The following chapter delineates the research methods that were employed to achieve this aim. 


\section{CHAPTER 3: RESEARCH DESIGN AND METHODOLOGY}

It is hypothesized that meaning making is a large contributor to the likelihood of a specific trauma trajectory outcome, such as PTSD, resiliency, and PTG. This study aimed to map the trauma trajectory using meaning making as the driving factor in determining the outcome (PTSD, resiliency, or PTG). It was hypothesized that if there was no violation of world beliefs following a stressful combat experience, resiliency emerged. If there was a violation of world beliefs following a stressful combat experience, and the individual coped actively and created meaning, PTG occurred. If there was a violation of world beliefs following a stressful combat experience and there was no active coping or meaning making that occurred, PTSD resulted. The following chapter outlines the research design and methodology that was used to test these hypotheses.

\section{Research Design}

As stated above, the purpose of this study was to address the relationship among meaning making, PTSD, resiliency, and PTG. A quantitative, causal modeling design using correlational data among the measures was utilized to examine these relationships. Because all measures in this study were continuous variables, no cutoff scores were used to determine the direction of the associations. Higher scores indicated greater association of the targeted variable assessed by the measure, whereas lower scores indicated lower presence of the target variable. As this study used correlational data to create a causal model, participants were not assigned to specific manipulations or conditions in the study.

The hypothesis of this study was to find support for the trauma trajectory model proposed by Larner and Blow (2011) by testing an adapted model found in figure 3. The proposed model hypothesized that if there were not a violation of world beliefs following a stressful combat 
experience, resiliency occurred. If there was a violation of world beliefs following a stressful combat experience and there was active coping and meaning making occurring, PTG resulted. If there was a violation of world beliefs following a stressful combat experience and there was no active coping or meaning making occurring, PTSD developed.

These hypotheses were tested through the implementation of a step through statistical process. Initially the model was tested using Path Analysis to determine the structure of the relationships between variables. Upon completion of the Path Analysis, the data were examined to determine that they met the criteria for multivariate normality. Upon finding multivariate normality, SEM was then used to measure the strength between the variables. The data were also explored through the use of descriptive statistics.

In order to determine the necessary sample size for this study, the literature on Path Analysis/SEM was consulted. In an article by Tanaka (1987), the author concluded that the rule of thumb for multiple regression analysis is to have a minimum of 5-10 observations per variable. As SEM uses multiple regressions, this also applies to Path Analysis/SEM based on the amount of parameters being estimated. According to Tanaka's (1987) estimate, with 11 variables in this study, a minimum of 110 participants would be necessary. Kline (2005) suggested that when using a Path Analysis/ SEM model, approximately 200 participants are ideal. Therefore, in order to ensure an adequate sample size and to prepare for the possibility of incomplete data, ideally, a participant sample of 200 veterans was sought for this study (Loehlin, 2004).

Descriptive Statistics. Descriptive statistics included the number of participants who took the survey, the range of scores, and the means, medians, modes, and standard deviations for all items. Data on all participant demographic information were measured and reported. Sex and length of deployment were proposed as covariates in the data analyses. However, the influence 
of the other demographic information on the model was also explored. SPSS Statistical Software version 20 was used for analysis of descriptive statistics.

Path Analysis. A Path Analysis approach was used to examine the structure of the relationships among the variables included in the hypothesized model. Path Analysis is a multivariate statistical approach used to determine associations among multiple variables. The analysis is a type of multiple regression analysis based upon correlational data. Therefore, causality from the results should be interpreted with caution. The Path Analysis was used to create a structural model based on the data. The data is presented in a path diagram in which the relationships among the variables are represented by arrows to signify the direction of influence. Both direct and indirect effects are estimated by this approach, and both are reported. Upon completion of the Path Analysis, the data was analyzed to assure that it met the criteria for multivariate normality. Following this, the analysis continued on to include testing of the model through the utilization of SEM analysis.

Structural Equation Modeling (SEM). Upon determining that the criteria for multivariate normality were met, a SEM approach was used to examine the correlations among the variables in relation to the hypothesized model. SEM is a multivariate statistical approach used to determine effects among multiple variables. The pattern of inter-correlations among the variables was tested for fit with the underlying theory to indicate which variables contribute to "causation" of other variables. The causal inferences must be interpreted with some caution however, as the data derives from a correlational design and not a true experimental design. The casual inferences are weaker using a SEM model than through a true experimental design. Nevertheless, due to the delimitations of the study, the use of SEM was deemed the most practical approach. The results from the SEM analysis are presented in a path diagram in which 
the effects among the variables are represented by arrows to signify the direction of influence.

Both direct and indirect effects can be estimated by this approach, and both are reported.

In order for SEM analysis to be used appropriately, specific assumptions must be met by the data. Assumptions for a SEM analysis include normality of variable distributions, limited skewness, independence of variables, and minimal measurement error. These assumptions were examined prior to analysis of the data. SAS Statistical Software was used to conduct the SEM analysis.

The hypothesized model that was initially tested is shown in Figure 3, below.

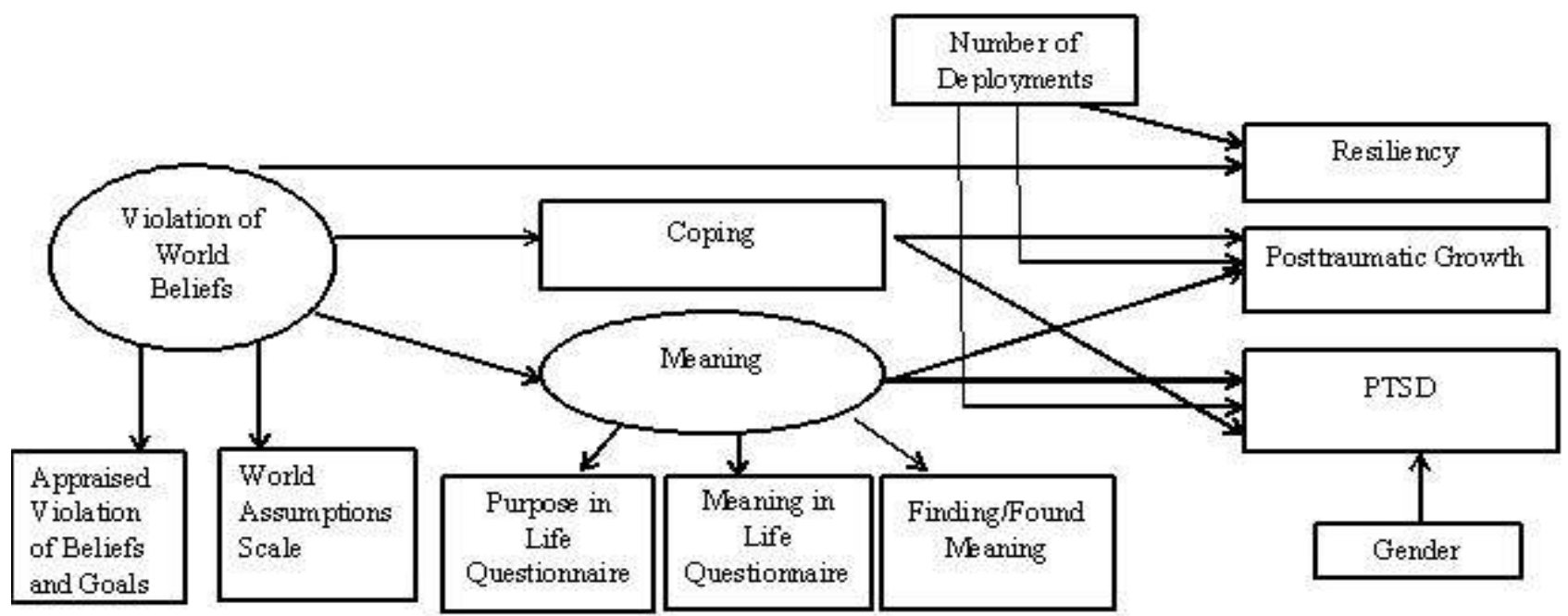

Figure 3. The proposed meaning making model/trajectory for veterans for this study.

In the proposed meaning making model for this study, violation of world beliefs was a latent variable that was composed of two different measures, the Appraised Violation of Beliefs and Goals questionnaire (Park, 2008) and the World Assumptions Scale (Janoff-Bulman, 1989; with this scale being recoded to create a homogenous direction of the two scales in use). It was hypothesized that lower combined scores on both measures would predict a higher score on the resiliency measure (the Brief Resiliency Scale; Smith et al., 2008). Conversely, it was 
hypothesized that higher combined score on both violation of world belief measures would predict individuals to score higher on either a measure of PTG (the Posttraumatic Growth Scale; Tedeschi \& Calhoun, 1996) or PTSD (the Posttraumatic Stress Disorder Checklist - Military; Weathers, Litz, Herman, Huska, \& Keane, 1993). Higher scores on the measure of PTSD were hypothesized to be further predicted by lower scores on a measure of coping (the Impact of Events Scale - Revised; Creamer, Bell, \& Failla, 2003) and a latent variable used to measure meaning making. The meaning making variable was comprised of the Meaning in Life Questionnaire (Steger, Frazier, Oishi, \& Kaler, 2006), the Purpose in Life Test (Crumbaugh \& Maholick, 1964/1969/1981), and the Finding/Found Meaning questions (created for this study), all of which are discussed in further detail in the measures section. Higher scores on the measure of PTG were hypothesized to be predicted by higher scores on the measure of coping and the measure of meaning making.

With regard to covariates, as discussed, females are at greater risk for developing PTSD (American Psychiatric Association, 2013). Therefore, sex was hypothesized to be a covariate that would affect scores on the PTSD measure. Although less well documented, the number of deployments are related to the amount of stressful experiences an individual may be exposed to and has been identified as a possible risk factor for PTSD as well (Shen et al., 2010). Due to this, number of deployments was also used as a covariate for all three of the outcome variables: PTSD, resiliency, and PTG.

\section{Participants}

Respondents were combat veterans of the United States Military. Inclusion criteria required that participants were deployed at least once and have served in OEF/OIF/OND during that time. Participants consisted of responders to an internet-based survey, solicited through 
emails to a nationwide student veteran organization, the Student Veterans of America and other veteran organizations targeted through social media.

Based on a 2011 Department of Defense report, the U.S. Military is comprised of approximately $85 \%$ males (including approximately $70 \%$ Caucasians, with $30 \%$ self-identifying as a minority). Therefore, it was the goal of this study to attempt to accurately represent the demographics of the military. In this study all participants were required to be over the age of 18 .

\section{Measures}

The measures that were used in the study are listed below along with the psychometric properties associated with each. This section includes an extensive review of the assessments that were used. The measures are organized based on the constructs they were purported to measure. The constructs included in this study were: violation of world beliefs, meaning, coping, PTSD, resiliency, and PTG. Violation of world beliefs was considered to be a latent variable within this study and measured by the Appraised Violation of Beliefs and Goals scale and the World Assumptions Scale. The construct of meaning was also considered to be a latent variable and was measured by the Meaning in Life Questionnaire, the Purpose in Life Test, and Finding/Found Meaning Questions. Coping was treated as a manifest variable and was measured with the Impact of Events Scale - Revised. The manifest variable of PTSD was measured with the Posttraumatic Stress Disorder Checklist. The manifest variable of resiliency was measured with the Brief Resilience Scale. The manifest variable of PTG was measured by the Posttraumatic Growth Inventory. The Combat Experiences Scale from the Deployment Risk and Resiliency Inventory (DRRI) was used to measure the amount of exposure the participants had to combatrelated events. 
As with all research, in order for researchers to test the proposed model, agreed upon measures of assessment are necessary. Currently, there are no widely accepted measures for the constructs of both violation of world beliefs or meaning making. Due to this, both constructs were measured by multiple questionnaires that each tap into different components of the overall construct. Thus, because this model uses multiple measures to create the constructs of both violation of world beliefs and meaning making, both variables were considered latent variables as opposed to manifest or observed variables.

A demographics form was also included in the study and is discussed in greater detail below. Upon completion of the study, Cronbach's alpha was calculated for all of the measures used and is reported in this section as well.

Violation of World Beliefs. This latent variable was made up of two different measures, the Appraised Violations of Beliefs and Goals Scale (Appendix B) and the World Assumptions Scale (Appendix C; initially recoded so both scales reported their results in a homogeneous direction). High scores on the latent variable violation of world beliefs were hypothesized to lead to a PTSD or PTG trajectory; whereas lower scores were hypothesized to lead to a resiliency trajectory.

Appraised Violations of Beliefs and Goals Scale (Park, 2008). The Appraised Violations of Beliefs and Goals Scale was developed for use in a study by Park (2008) and measured meaning-making related to a traumatic loss. In the present study, the measure was revised for the applicability to the current population of interest (e.g., the term "traumatic loss" was changed to "being in combat"). Belief violations were measured through five questions in which participants rated the degree to which their experience violated prior held beliefs on a four-point scale ranging from one (not at all) to four (very much). Goal violations were assessed by asking 
participants to rate the extent to which their combat experience interfered with their ability to accomplish any life goals on the same four point scale as belief violations. Items included, "When you think about how you felt before and then after being in combat, how much did the experience violate your sense of the world being fair or just?" Higher scores on the measure originally indicated a greater degree of inferred violation of world beliefs. In order to create a homogeneous latent variable, during data analysis, this scale was reverse coded (discussed later in this dissertation). Thus, higher scores on the measure then indicated a lower degree of inferred violation of world beliefs.

A modest, significant inter-correlation between the items was previously found. In a validation study, the scale yielded a Cronbach's alpha coefficient of .88 (Park, 2008). For this study, the Cronbach's alpha coefficient was found to be 0.80 , which is considered to be in the "good" range (see Table 1). 


\begin{tabular}{|c|c|c|c|c|}
\hline Scale Name & $\begin{array}{l}\text { Number } \\
\text { of Items }\end{array}$ & $\begin{array}{l}\text { Number of } \\
\text { Participants }\end{array}$ & Cronbach's Alpha & Qualitative Label $^{1}$ \\
\hline $\begin{array}{l}\text { World Assumptions } \\
\text { Scale }\end{array}$ & 32 & 131 & 0.884 & Good \\
\hline $\begin{array}{l}\text { Meaning in Life } \\
\text { Questionnaire }\end{array}$ & 10 & 143 & 0.694 & Acceptable \\
\hline $\begin{array}{l}\text { Meaning in Life } \\
\text { Questionnaire } \\
\text { Presence Subscale }\end{array}$ & 5 & 143 & 0.931 & Excellent \\
\hline $\begin{array}{l}\text { Meaning in Life } \\
\text { Questionnaire } \\
\text { Search Subscale }\end{array}$ & 5 & 143 & 0.895 & Excellent \\
\hline $\begin{array}{l}\text { Posttraumatic Stress } \\
\text { Disorder Checklist } \\
\text { (Combined Form) }\end{array}$ & 21 & 140 & 0.964 & Excellent \\
\hline $\begin{array}{l}\text { Posttraumatic Stress } \\
\text { Disorder Checklist } \\
\text { (Military) }\end{array}$ & 17 & 140 & 0.956 & Excellent \\
\hline $\begin{array}{l}\text { Posttraumatic Stress } \\
\text { Disorder Checklist } \\
\text { (5) }\end{array}$ & 20 & 140 & 0.963 & Excellent \\
\hline $\begin{array}{l}\text { Post-Traumatic } \\
\text { Growth Inventory }\end{array}$ & 21 & 135 & 0.950 & Excellent \\
\hline $\begin{array}{l}\text { Brief Resilience } \\
\text { Scale }\end{array}$ & 6 & 140 & 0.909 & Excellent \\
\hline $\begin{array}{l}\text { Impact of Events } \\
\text { Avoidance Subscale }\end{array}$ & 8 & 136 & 0.874 & Good \\
\hline $\begin{array}{l}\text { Apprised Violation } \\
\text { of Beliefs and Goals }\end{array}$ & 6 & 140 & 0.803 & Good \\
\hline $\begin{array}{l}\text { Purpose in Life } \\
\text { Scale }\end{array}$ & 20 & 143 & 0.945 & Excellent \\
\hline
\end{tabular}

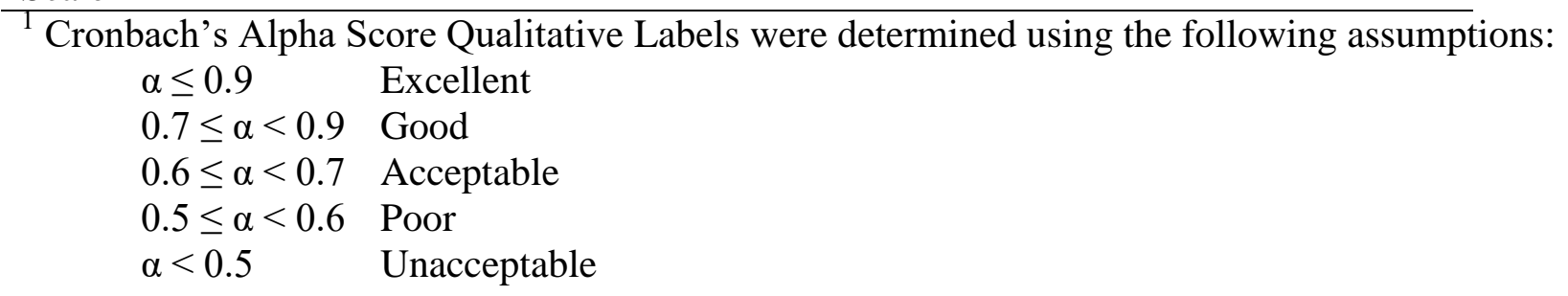

Table 1. Cronbach's Alpha scores for measures. 
The World Assumptions Scale (WAS; Janoff-Bulman, 1989). The WAS is commonly used to correlate the measurement of appraised violations of beliefs with assumptions about the world (Kaler et al., 2008). The WAS is a 32-item measure with eight subscales that assesses each of the world assumptions described by Janoff-Bulman (1989): benevolence of the impersonal world, benevolence of people, randomness, justice, controllability, self-worth, self-control, and luck. These subscales assess three categories of assumptions: meaningfulness or explicability of events, self-worth, and perceived benevolence of the world and people in general. A sample question is, "Generally, people deserve what they get in this world". Responses are based on a six-point Likert scale ranging from one (strongly disagree) to five (strongly agree). Cutoff scores are not used for this measure, and WAS mean scores were handled as a continuous variable. Higher scores on this measure indicate a greater degree of intact world beliefs. Initially, the scores on this measure were reverse coded in order to create a homogeneous latent variable. However, during data analysis, this Appraised Violation of Beliefs and Goals scale was reverse coded and the WAS scores were coded as initially intended by the authors; (the reasoning for this change is discussed later in the chapter).

While the WAS has not been validated on a military population, it has been previously used in a general community sample. Internal consistency reliability was been found to be acceptable with alpha levels ranging from .68 to.89 (Elklit et al., 2007). For this study, the Cronbach's alpha coefficient was found to be 0.88 , which is considered to be in the "good" range (see Table 1). Test-retest data for a sample of individuals that had experienced a combat trauma was not available (Elklit et al., 2007; Kaler et al., 2008). Convergent validity has been demonstrated through the WAS subscales and the Harvard Trauma Questionnaire (HTQ) with stronger PTSD symptoms related to stronger shattered assumptions $(r=.08$ to -.43 , when 
appropriately reverse scored) between PTSD symptom clusters and shattered assumptions (Elklit et al., 2007). Discriminant validity scores were not available.

Meaning. The latent variable, "meaning”, was made up of three measures: the Meaning in Life Questionnaire (Appendix D), the Purpose in Life Test (Appendix E), and Finding/Found Meaning questions (Appendix F). In conjunction with high scores on the coping scale, high scores on meaning were hypothesized to lead to a PTG trajectory; whereas lower scores (also in conjunction with low scores on the coping scale) were hypothesized to lead to a PTSD trajectory.

The Meaning in Life Questionnaire (MLQ; Steger, Frazier, Oishi, \& Kaler, 2006). The MLQ assesses two dimensions of meaning in life: how respondents experience the level of meaning in their lives and how engaged and motivated respondents are in efforts to find meaning or deepen their understanding of meaning in their lives through questions such as "I understand my life's meaning". The MLQ is a 10-item measure that utilizes a seven-point Likert scale with responses ranging from one (absolutely untrue) to seven (absolutely true). The MLQ has two subscales: Presence of Meaning and Search for Meaning. The MLQ has a possible score range of 10 to 70 with each subscale having a possible scoring range of five to 35 . However, for this study, scores were averaged for use in the analysis and then handled as a continuous variable. Higher scores on the Presence subscale indicate a greater level of presence of meaning in the respondent's life, whereas higher scores on the Search subscale indicate a greater level of active searching for meaning by the respondent.

The MLQ demonstrated good psychometric properties in an initial validation study (Steger et al., 2006). Other validation studies have not been conducted. The MLQ has not been validated on a military population. However, the following validity data is available from a college student sample. According the Steger et al. (2006), the one- month test-retest reliability 
of the MLQ was strong with stability coefficients ranging from .70 to .73. Internal consistency of the subscales was also strong, with Cronbach's alphas ranging from .81 to .92. For this study, the full scale Cronbach's alpha coefficient was found to be 0.69 , which is considered to be in the "acceptable" range. When the MLQ subtests were viewed separately the Presence subscale had a coefficient of 0.93 and the Search subscale had a coefficient of 0.90 , both considered to be in the “excellent” range (see Table 1). Evidence for convergent validity was found between the MLQ, the Purpose in Life Test (PIL), and the Life Regard Index (LRI) with significant correlations ranging from .58 to .74 . To demonstrate discriminant validity, the MLQ was compared to scales that measured well-being (i.e., Rosenberg Self-Esteem Inventory, EST; Satisfaction with Life Scale, SWL; Life Orientation Test, LOT), and coefficients ranged between .38 and .50 .

Purpose in Life Test (PIL; Crumbaugh \& Maholick, 1964/1969/1981). The PIL is one of the most thoroughly researched measures within logotherapy and meaning making. It was deigned to examine an individual's self-reported level of current purpose and meaning within their life (Guttmann, 1996; Hutzell, 1989; Reker, 2000). The PIL is grounded in Viktor Frankl's concept of the will to meaning, which indicates that a person continuously strives to find purpose and meaning in life. The PIL is composed of three subscales, each with different formats: 1) Likert-type responses, 2) sentence completions, and 3) free responses. For the purpose of this study, only the first subscale (Part A), which consists of Likert-type response patterns, was used. Part A of the PIL asks respondents to rate their agreement on a one through five scale that corresponds to their agreement for 20 items. For example, participants are asked to rate their response to complete the statement "My personal existence is:" with a response of 1 corresponding to "utterly meaningless, without purpose" and a 5 corresponding to "purposeful and meaningful." Higher scores indicate greater purpose in life, and lower scores indicate lower 
or missing purpose in life. Scores of 113 and above are suggestive of a purpose in life, scores that fall between 92 and 112 are suggestive of indeterminate purpose in life, and scores of 91 or less suggest a lack of life purpose (Crumbaugh \& Maholick, 1964; Guttman, 1996). Although this measure has been used to categorically distinguish different groups of individuals, for the purposes of this study, scores were averaged and treated continuously.

Internal reliability estimates of the PIL have typically exceeded .80 or .90 (Crumbaugh, 1968; Sink, van Keppel, \& Purcell, 1998). For this study, the Cronbach's alpha coefficient was found to be 0.94 , which is considered to be in the "excellent" range (see Table 1). Reliability studies have evaluated the measure in both rural and metropolitan area high school students. Test-retest reliabilities have been reported in the .66 to .78 range. Test-retest reliability in one of the most recent studies with the measure was .91 (Schulenberg, 2004).

Construct validity for the PIL has also been demonstrated (Chamberlain \& Zika, 1988; Crumbaugh, 1968; Crumbaugh \& Henrion, 1988; Hutzell, 1988). The PIL was positively correlated with extroversion and happiness (Hutzell, 1988, 1989) and negatively correlated with depression and anxiety (Robak \& Griffin, 2000).

Finding/Found Meaning. The Finding/Found Meaning items were two additional face valid questions that were added to the questionnaire to obtain a self-report of participant belief in searching for or finding meaning from combat experience. The questions were created by the author for this study. The questions were modeled after questions included in a study by Park (2008). Finding meaning or the search for meaning was measured with the question "How much have you been trying to make sense of, or find, any meaning in your experience?" Found meaning was measured with the question "Do you believe that you have been able to make sense of, or find, any meaning in your experience?" For both questions, participants responded on a 
four point Likert-like scale ranging from one (not at all) to four (very much). As these questions were created for this study, no psychometric properties were previously available. For this study, the scores on this measure were averaged for use in the analysis and then handled as a continuous variable.

Coping. The manifest variable, "Coping”, was measured by the Impact of Events Scale Revised (Appendix G). In conjunction with high scores on the meaning variable, high scores on coping were hypothesized to lead to a PTG trajectory; whereas lower scores (also in conjunction with low scores on the meaning scale) were hypothesized to lead to a PTSD trajectory.

Impact of Events Scale - Revised (IES-R; Creamer, Bell, \& Failla, 2003). The IES-R is a 22-item scale used to assess the impact of a traumatic or stressful event on the constructs of intrusion, avoidance, and hyperarousal. Participants indicated how distressed or bothered they have been by each of the 22 items during the past week with respect to their time in combat. The participants rated their level of difficulty in dealing with traumatic experiences on a five point Likert-type scale that ranged from zero (not at all) to four (extremely) on questions such as "I stayed away from reminders of it".

Scores on the IES-R avoidance subscale were averaged to determine a coping score, with higher scores indicating a greater impact of events. The scale has been studied extensively in different populations but was initially created to measure Vietnam veteran response to traumatic or stressful combat experiences (Park, 2008). Internal consistency of the measure was high with a Cronbach's alpha coefficient of .96 (Park, 2008). The correlation between the IES-R and the PTSD Checklist was found to be high with a correlation coefficient equal to .84. For this study, the Cronbach's alpha coefficient was found to be 0.87 , which is considered to be in the "good" range (see Table 1). Additionally, a full scale score of 33 was found to provide accurate PTSD 
diagnosis when compared to expert diagnosis (Park, 2008). However, for this study cutoffs were not used, only scores on the avoidance subscale were averaged for use in the analysis and then handled as a continuous variable. Having a continuous variable is a requirement for the statistical analysis that was conducted.

Posttraumatic Stress Disorder (PTSD). The manifest variable, "Posttraumatic Stress Disorder", was measured by the Posttraumatic Stress Disorder Checklist (Appendix H). This is one of the three outcome variables measured within this study. A high score on violation of world beliefs, a low score on meaning, and a low score on coping variables were hypothesized to predict a high score on PTSD.

\section{Posttraumatic Stress Disorder Checklist (PCL; Weathers, Litz, Herman, Huska, \&}

Keane, 1993). One of the most commonly used measures for diagnosis of PTSD in military populations is the Posttraumatic Stress Disorder Checklist (PCL; Weathers et al., 1993). The PCL-M is a specific form of the measure that has been validated for military populations (Wilkins, Lang, \& Norman, 2011). The PCL-M is a 17-item measure that assesses PTSD symptomology based on the Diagnostic and Statistical Manual of Mental Disorders (DSM-IVTR) criteria. Individuals are asked to rate the degree to which they have been bothered by symptoms related to stressful military experiences in the past month on a five point Likert-type scale ranging from 1 (not at all) to 5 (extremely) on questions such as "repeated, disturbing memories, thoughts, or images of a stressful military experience?". Scores can range from 17 to 85, with higher scores indicating greater severity of PTSD. Cutoff scores vary depending on the setting in which the assessment is being used. For this study, cutoff scores were not used and PCL scores were averaged and handled as a continuous variable. 
The psychometric properties of the PCL-M have been demonstrated in initial validation studies (Weathers, Litz, Huska, \& Keane, 1994). More recently, large-scale examinations have explored the psychometric properties of the measure across multiple studies (Wilkins et al., 2011). The psychometric properties of the PCL-M in initial validation studies are similar to the psychometric properties found in larger scale assessments of the measure (Weathers et al., 1993; Wilkins et al., 2011).

The following psychometric data is based on a large-scale meta-analysis of 73 studies that looked at the PCL-M with veteran samples (Wilkins, Lang, \& Norman, 2011). Test-retest reliability was reported at or above .70 after 2 to 3 days. Internal consistency scores range from approximately .75 to above .80 . For this study, the Cronbach's alpha coefficient was found to be 0.96, which is considered to be in the "excellent" range (see Table 1). The PCL-M tends to have moderate to high correlations with measures of anxiety, depression, and quality of life. Strong convergent validity has been found through the comparison of the PCL-M to the PTSD section of Structured Clinical Interview for DSM Axis-I Disorders (SCID), yielding a kappa coefficient of .64. Convergent validity has also been demonstrated through comparison of the PCL-M to the Clinician Administered PTSD Scale (CAPS), the Impact of Events Scale (IES), and the SCID with correlations ranging from .62 to .90 . Discriminant validity has also been found between the PCL-M and the Beck Depression Inventory - II (BDI-II), the Cognitive Distortions Scale (CDS), the State-Trait Anxiety Expression Inventory-2 (STAXI-2), and the Trauma Related Guilt Inventory (TRGI) with correlations ranging from .29 to.47.

A newer version of the PCL has been created to fit the diagnostic criteria outlined within the new DSM-5. The new version is a 20 item survey in the same form as the PCL-M. The research on the psychometric properties of this measure is still being conducted. However, for 
this study, the Cronbach's alpha coefficient was found to be 0.96 , which is considered to be in the "excellent" range (see Table 1). Other studies have used a combined measure of the PCL-M and the PCL-5 (J. Scotti, personal communication, April 17, 2014) and the present study followed this procedure. Both PCL-M and PCL-5 scores were obtained and compared for similarities. The combined score yielded a Cronbach's alpha coefficient of 0.96, which is also considered to be in the "excellent" range. Further results will be shared and discussed at the conclusion of the study.

Resiliency. The manifest variable, "Resiliency", was measured by the Brief Resilience Scale (Appendix I). This is the second of the three outcome variables measured within this study. A low score on violation of world beliefs was hypothesized to predict a high score on resiliency.

The Brief Resilience Scale (BRS; Smith et al., 2008). The BRS was developed to measure the ability of an individual to rebound or recover from a stressful event (Smith et al., 2008). The BRS is a six-item measure that assesses the degree of individual resilience following a stressful event. Individuals are asked to rate the degree to which they agree with the questions on a five point Likert-type scale ranging from 1 (strongly disagree) to 5 (strongly agree) to questions such as "I tend to bounce back quickly after hard times," "It does not take me long to recover from a stressful event," and "I usually come through difficult times with little trouble." Scores can range from six to 30, with higher scores indicating greater resiliency. Cutoff scores were not used; scores were averaged for use in the analysis and then handled as a continuous variable.

The initial validation study of the BRS by Smith et al. (2008) examined the measure's psychometric properties. However, additional studies to replicate the psychometric properties have not been conducted. As such, the psychometric properties listed below are from the initial 
validation study of the BRS by Smith et al. (2008). While the BRS has not been validated on a military population, the psychometric data listed below are from a college student sample. Internal consistency was found to be strong, with Cronbach's alpha coefficients ranging from .80 to .91. For this study, the Cronbach's alpha coefficient was found to be 0.91 , which is considered to be in the "excellent" range (see Table 1). Test-retest reliability was found to be $r=$ .69 after one month and $r=.62$ after three months. Convergent validity was demonstrated though the significant positive correlation of the BRS and other resiliency measures (ConnorDavidson Resilience Scale, CD-RISC; the Ego Resiliency Scale), optimism (Life Orientation Test-Revised), and the Purpose in Life Test. Correlations between the BRS and these measures range from .51 to.67. Discriminant validity was demonstrated through negative correlations of pessimism and negative affect through the use of the Type D Personality Assessment ranging from -.61 to .23 .

Much of the validation of this measure has been on a college sample. For the purposes of this study, the majority of respondents were expected to also be from a college sample. Therefore, it was believed that the psychometric properties in this study would be similar to previous validation studies.

Posttraumatic Growth (PTG). The manifest variable, "Posttraumatic Growth", was measured by the Posttraumatic Growth Inventory (Appendix J). This is the last of the three outcome variables measured within this study. High scores on violation of world beliefs, meaning, and coping variables were hypothesized to predict a higher score on PTG.

The Posttraumatic Growth Inventory (PTGI; Tedeschi \& Calhoun, 1996). The PTGI was developed to measure positive changes occurring after a traumatic event (Tedeschi \& Calhoun, 1996). The PTGI is a 21-item measure to assess the degree to which an individual has 
experienced growth in the following categories: new possibilities, relating to others, personal strength, spiritual change, and appreciation of life. Individuals are asked to rate the degree to which the changes occurred in their life as a result of the traumatic event on a six point Likerttype scale ranging from 0 ("I did not experience this change") to 5 ("I experienced this change to a very great degree") to statements such as "knowing I can handle difficulties." Scores can range from 0 to 105, with higher scores indicating stronger levels of PTG. For this study cutoff scores were not used, scores were averaged for use in the analysis and then handled as a continuous variable.

Initial psychometric properties of the PTGI were reported by Tedeschi and Calhoun (1996), and additional studies have further supported the utility of the measure (Lee, Luxton, Reger, \& Gahm, 2010). The most extensive examination of the measure's psychometric properties was conducted during the initial validation study and consisted of a sample of college students (Tedeschi \& Calhoun, 1996). Internal consistency of the PTGI is reported to be $\alpha=.90$. For this study, the Cronbach's alpha coefficient was found to be 0.95 , which is considered to be in the "excellent" range (see Table 1). Test-retest reliability across a two-month span was found to be acceptable at $r=.71$. Concurrent validity was demonstrated with a scale of optimism, the Life Orientation Test (LOT, $r=.76$ ). The NEO Personality Inventory was used to assess discriminant validity among the correlations of PTGI and personality characteristics; correlations were found in the expected direction between neuroticism $(r=-.71)$, extraversion $(r=.20)$, and openness to new experiences $(r=.19)$.

The original PTGI scale asks respondents to indicate whether they experienced change “as a result of my crisis". However, in a recent study by Lee et al. (2010), the instructions were revised to ask military respondents whether they experienced change "as a result of their 
deployment or combat experience." This change was made because many military members do not view their combat experiences as a crisis and may subsequently bias the results of the assessment (Lee et al., 2010). The change in instructions was not found to have a significant effect on the validity or reliability estimates of the measure when changed by Lee and colleagues (2010). Thus, the revised version of the instructions, tailored for military samples, was used for this study.

Covariates. Sex and number of deployments were believed to be two covariates within the current model. Because females are at greater risk for developing PTSD, sex was considered a covariate for PTSD. A greater number of deployments are expected to increase the amount of stressful combat situations that a participant is exposed to and therefore was considered a covariate for all three trajectory outcomes. Other demographic data (e.g., ethnicity, age, and spirituality/religiosity) were examined post hoc to determine if they influenced the structure or strength of the model.

Demographics Questionnaire. Included in the measurements was a self-report demographics section with questions regarding participant age, gender, the state that they currently live in, ethnicity, number of deployments, length of each deployment, and location of each deployment (Appendix L). Additionally, participants were asked about their level of education, branch of the military, military grade, income level, level of self-perceived religiosity or spirituality, incidences of traumatic brain injuries, chronic pain resulting from combat injury, social supports, and if they received any mental health services upon returning from combat. As stated previously, sex and length of deployment were measured and included as covariates in the data analyses. 
Combat Experience (King, King, \& Vogt, 2003). Included in the measurements was also a self-report questionnaire on the veteran's combat exposure. The questionnaire was taken from the Deployment Risk and Resiliency Inventory (DRRI; King, King \& Vogt, 2003). The measure is an 18 question survey in which respondents endorse whether they have experienced each event in a yes or no format. Some of the questions from the assessment are: "I was stationed in a conflict area and under threat of enemy fire;" "I went on dangerous duties, such as combat patrols, sorties, convoys, and route and mine clearance;" and "I encountered land or water mines, booby traps, or IEDs."

The Combat Experiences scale has been tested with over 2,000 OEF/OIF/OND veterans and has demonstrated sound psychometric properties. The Combat Experiences scale has strong internal consistency reliability. Expected correlations were observed between the scale and a measure of PTSD symptom severity, providing support for criterion-related validity (King, King, \& Vogt, 2003).

The data from the Combat Experiences scale were gathered in order to possibly capture a significant factor in predicting PTSD responses based on combat exposure. Combat experiences have been strongly associated with the development of PTSD signs and symptoms in much of the literature.

\section{Procedure}

In this study I utilized an Internet survey format to gather data. The research was reviewed and approved by the West Virginia University Institutional Review Board (WVU IRB; Appendix A). After receiving approval, a link to the survey was emailed to all of the Student Veterans of America campus chapters across the nation for dissemination to their members. The link was also posted on various veteran organization social media websites. The WVU IRB form 
and an explanation of the study were available on the website for prospective participants to view before accepting to participate in the study.

Participants who chose to follow the link to the survey were directed to a website hosted by the company Qualtrics. When participants clicked on the link, they were directed to the introductory page of the survey, which contained the informed consent (see Appendix A). In order to maintain confidentiality, participants were not asked for their names or any other identifying personal information during the survey. Participants indicated their consent to participate in the study by clicking the button that corresponded to the statement "I have read the above information, I certify that I am at least 18 years old, and agree to be in this study. Checking this box will take me to the survey" at the bottom of the informed consent page. This button then directed them to the first page of the survey. Conversely, participants could choose to click the button that corresponded to the statement "I do not want to be in this study. Checking this box will take me out of the survey." Participants who chose this option were directed out of the survey and to a screen that thanked them for their participation.

Upon completion of the informed consent page, the participants were asked if they had been deployed in military combat. If the participant indicated that they had not been deployed, the survey concluded. If the participant indicated that they had been deployed, they were then asked to choose the amount of time they have been home since their last deployment. Regardless of the amount of time indicated, the survey continued. Participants were then presented with the measurement instruments (see Appendices B-K) and then demographics form.

The demographics form was always presented to the participants last due to the possible sensitive nature of some of the questions and risk of priming. However, the order in which the other measures were presented was randomized by the Qualtrics website. Each measure was 
displayed on a separate page. Upon completing each measure, the participants clicked a button which took them to the next measure until all measures had been completed.

Aside from consent to participate and whether the participant had been in combat, none of the individual questions were mandatory. The participants were able to change their responses at any time before they completed and submitted the questionnaire. Upon completion of the entire survey, participants were taken to a page with a note of appreciation for participation in the survey, the Veteran's Crisis Line phone number, and contact information for the principal investigator. The participants then had the option of being entered into a drawing to win one of three $\$ 25$ Visa Gift Cards. If the participants wanted to be entered into the drawing, they were directed to a separate page where they entered their name and email address. This information was kept separately from their data and was deleted following the drawing. The entire questionnaire took approximately 30 minutes to complete. Information entered by the participants was collected in the secure Qualtrics database and was stored as a spreadsheet that was analyzed using SAS and SPSS upon completion. 


\section{CHAPTER 4: RESULTS}

\section{Demographics}

During data collection, a total of 194 participants agreed to participate in the study. Nineteen participants were excluded from the study due to not meeting the study requirement of having served in combat and nine were excluded due to not completing any of the measures. Due to using the Full Information Maximum Likelihood (FIML) procedure, incomplete responses were included in the study as long as a minimum of one of the scales were completed. Thus, 166 participants were included in the data analysis for this study. Of those 166 participants, 119 surveys were fully completed and 47 surveys were partially completed. Of the participants, 99 were male (59.6\%) and 23 were female (13.9\%) and 44 did not respond (26.5\%), relatively comparable to the larger US military, where $85 \%$ identify as male (Department of Defense, 2011). The mean participant age was $34.08(\mathrm{SD}=9.17, \mathrm{n}=109)$. The participant age range was between 22 and 67 years of age.

Participants reported the state they were currently living in. By self-report, twenty-six states were represented in this sample. The most frequently reported states were West Virginia $(\mathrm{n}=28,16.9 \%)$, North Carolina $(\mathrm{n}=14,8.4 \%)$, and Virginia $(\mathrm{n}=10,6.0 \%)$. Additional characteristics of participants represented in this sample can be found in Table 2. Using the Census Regions and Division of the United States and the valid percentages of the respondents, the largest reported region of respondents was from the South $(n=72,60 \%)$. The Pacific was least represented $(\mathrm{n}=1,1 \%)$. The remaining respondents were relatively evenly divided among the West $(n=17,14 \%)$, Midwest $(n=16,13 \%)$, and the North East $(n=15,12 \%)$. 


\begin{tabular}{|c|c|c|}
\hline & $\begin{array}{l}\text { Number of } \\
\text { Participants }\end{array}$ & $\begin{array}{c}\text { Valid } \\
\text { Percentage }\end{array}$ \\
\hline \multicolumn{3}{|l|}{ State } \\
\hline Arizona & 1 & $0.8 \%$ \\
\hline California & 8 & $6.6 \%$ \\
\hline Colorado & 3 & $2.5 \%$ \\
\hline Connecticut & 8 & $6.6 \%$ \\
\hline Florida & 2 & $1.7 \%$ \\
\hline Georgia & 3 & $2.5 \%$ \\
\hline Hawaii & 1 & $0.8 \%$ \\
\hline Idaho & 1 & $0.8 \%$ \\
\hline Illinois & 3 & $2.5 \%$ \\
\hline Indiana & 2 & $1.7 \%$ \\
\hline Iowa & 1 & $0.8 \%$ \\
\hline Kansas & 1 & $0.8 \%$ \\
\hline Kentucky & 2 & $1.7 \%$ \\
\hline Louisiana & 2 & $1.7 \%$ \\
\hline Maine & 1 & $0.8 \%$ \\
\hline Massachusetts & 3 & $2.5 \%$ \\
\hline Missouri & 1 & $0.8 \%$ \\
\hline New Jersey & 3 & $2.5 \%$ \\
\hline North Carolina & 14 & $11.6 \%$ \\
\hline Ohio & 5 & $4.1 \%$ \\
\hline Oklahoma & 2 & $1.7 \%$ \\
\hline Oregon & 1 & $0.8 \%$ \\
\hline Tennessee & 1 & $0.8 \%$ \\
\hline Texas & 8 & $6.6 \%$ \\
\hline Virginia & 10 & $8.3 \%$ \\
\hline Washington & 2 & $1.7 \%$ \\
\hline West Virginia & 28 & $23.1 \%$ \\
\hline Wisconsin & 3 & $2.5 \%$ \\
\hline Wyoming & 1 & $0.8 \%$ \\
\hline Did Not Respond & 45 & --- \\
\hline \multicolumn{3}{|l|}{ Deployment Location } \\
\hline Afghanistan & 59 & $35.5 \% *$ \\
\hline Gulf War I/Operation Desert Storm & 9 & $5.4 \% *$ \\
\hline Iraq & 87 & $52.4 \% *$ \\
\hline Kosovo & 6 & $3.6 \% *$ \\
\hline Kuwait & 31 & $18.7 \% *$ \\
\hline Saudi Arabia & 9 & $5.4 \% *$ \\
\hline Uzbekistan & 1 & $0.6 \% *$ \\
\hline Vietnam & 3 & $1.8 \% *$ \\
\hline Surrounding Middle Eastern States ${ }^{1}$ & 9 & $5.4 \% *$ \\
\hline Other Conflict Zone ${ }^{2}$ & 18 & $10.8 \% *$ \\
\hline
\end{tabular}




\begin{tabular}{|c|c|c|}
\hline \multicolumn{3}{|l|}{ Military Grade } \\
\hline E-2 & 1 & $0.8 \%$ \\
\hline E-3 & 3 & $2.5 \%$ \\
\hline E-4 & 33 & $27.3 \%$ \\
\hline E-5 & 39 & $32.2 \%$ \\
\hline E-6 & 14 & $11.6 \%$ \\
\hline E-7 & 8 & $6.6 \%$ \\
\hline E-9 & 2 & $1.7 \%$ \\
\hline $\mathrm{W}-2$ & 2 & $1.7 \%$ \\
\hline $\mathrm{W}-4$ & 2 & $1.7 \%$ \\
\hline O-3 & 9 & $7.4 \%$ \\
\hline O-4 & 2 & $1.7 \%$ \\
\hline O-5 & 3 & $2.5 \%$ \\
\hline O-6 & 3 & $2.5 \%$ \\
\hline Did Not Respond & 45 & --- \\
\hline \multicolumn{3}{|l|}{ Military Branch } \\
\hline Air Force & 10 & $8 \% *$ \\
\hline Army & 82 & $68 \% *$ \\
\hline Marines & 27 & $22 \% *$ \\
\hline Navy & 11 & $9 \% *$ \\
\hline Coast Guard & 1 & $1 \% *$ \\
\hline \multicolumn{3}{|l|}{ Reason for Seeking Treatment } \\
\hline Anxiety & 44 & $36 \% *$ \\
\hline Bipolar Disorder & 5 & $4 \% *$ \\
\hline Depression & 45 & $37 \% *$ \\
\hline Posttraumatic Stress Disorder & 55 & $45 \% *$ \\
\hline Readjustment Issues & 32 & $26 \% *$ \\
\hline Schizophrenia & 1 & $1 \% *$ \\
\hline Suicide & 10 & $8 \% *$ \\
\hline Other $^{3}$ & 16 & $13 \% *$ \\
\hline
\end{tabular}

*Many participants reported more than one deployment location/ branch of the military/ reason for seeking mental health treatment, thus percentages can total to greater than $100 \%$.

${ }^{1}$ Participants identified locations of deployments to "Surrounding Middle Eastern States" as: Jordan, Armenia, Egypt, Libya, Qatar, Republic of Georgia, and "Classified"

${ }^{2}$ Participants identified locations of deployments to "Other Conflict Zones" as: Africa, Beirut, Bosnia, Libya, Haiti, Macedonia, Serbia, Horn of Africa, Israel, Operation Odyssey Dawn, Panama, El Salvador, Somalia, Persian Gulf Coast, South Korean DMZ, and "classified"

${ }^{3}$ Of those who selected other, they reported their reason for entering treatment was related to: alcohol/drug abuse, anger, mood swings, career transition concerns, insomnia, marriage counseling, chronic pain, military sexual abuse, nightmares, survival guilt, and traumatic brain injury.

Table 2. Demographics of participants. 
Participants were asked to indicate their ethnicity by selecting all ethnicities that applied to them. The majority of participants indicated their ethnicity was "white" (n=100, 60.2\%). The remaining participants identified as Hispanic or Latino $(n=11,6.6 \%)$, Black or African American $(\mathrm{n}=8,4.8 \%)$, Asian/Pacific Islander $(\mathrm{n}=8,4.8 \%)$, Native American or American Indian $(\mathrm{n}=2$, $1.2 \%)$, and other $(n=2,1.2 \%)$. Seven participants reported two or more ethnicities. Forty-three participants did not respond. In comparison, the US military is comprised of approximately $70 \%$ Caucasians, with 30\% self-identifying as a minority (Department of Defense, 2011).

Unless otherwise specified, the remainder of the percentages reported in this chapter are valid percentages of only those that responded. The most frequently reported level of education for participants was "some college" $(\mathrm{n}=46,38.3 \%)$. The most frequently reported level of income was middle class $(n=36,29.8 \%)$. Of the participants, 44 participants $(36.4 \%)$ reported experiencing a traumatic brain injury while in combat. Additionally, 55 participants $(45.5 \%)$ reported that they sustained an injury during combat that has led to a permanent physical disability or chronic pain.

Participants reported that the average number of deployments they had was 3.22 $(\mathrm{SD}=1.35)$. The average time since returning from combat was reported to be four years $(\mathrm{SD}=$ 1.98). They reported the length of their deployment varying from between one month and 48 months. The average deployment length for participants in this sample was 10.93 months $(\mathrm{SD}=5.25)$. Both the median and mode of deployment length for the sample were 12-month deployments. Participants were able to select all of the locations in which they had been deployed, due to participants having multiple deployments, the reported percentages indicate how many participants served in each location and thus total greater than $100 \%$. The most 
frequently reported deployment locations were Iraq $(n=87,52.4 \%)$ and Afghanistan $(n=59$, $35.5 \%$ ). Additional deployment locations represented in this sample can be found in Table 2 .

Participants were asked their military grade. The largest percentage of participants reported being enlisted with a rank of E-5 $(n=39,23.5 \%)$. However, there was a large variability in respondents' rank. Officers were also represented in this study, with the most common officer rank being that of $\mathrm{O}-3(\mathrm{n}=9,5.4 \%)$. Additional military grades represented in this sample can be found in Table 2. Participants were also asked in which branch of service they served. The most commonly reported branch of service was the Army $(n=82)$. All branches of the military were represented; please see Table 2 for statistics related to additional branches of service represented within this study.

Participants were asked if they had received mental health treatment since they had returned from combat. Seventy-five participants $(61.5 \%)$ reported that they had received mental health treatment since they returned from combat. Forty-seven participants reported that they had not received mental health treatment since they had returned from combat $(38.5 \%)$. Of those that reported receiving mental health treatment, participants were asked to indicate their reason for seeking treatment. Due to participants having the ability to indicate that they sought treatment for multiple concerns, the response percentages total greater than $100 \%$. Posttraumatic Stress Disorder was the most commonly reported reason for seeking treatment $(n=55,45 \%)$. Please see Table 2 for statistics related to mental health treatment represented within this study.

The average reported level of religiosity/spirituality on a 1-5 point Likert-like scale was a $2.67(\mathrm{SD}=1.36)$, in which a response of 1 indicated they viewed themselves as "not religious or spiritual at all" and a response of 5 indicated that they viewed themselves as "very religious or spiritual." The average reported level of social support on a 1-5 Likert-like scale was 3.71 
$(\mathrm{SD}=1.15)$, in which a response of 1 indicated that they viewed their social supports as "not supportive at all" and a response of 5 indicated that they viewed their social supports as "very supportive". The average reported level of family support since returning from combat on a 1-5 point Likert-like scale $3.98(\mathrm{SD}=1.22)$, in which a response of 1 indicated that they viewed their family support as "not supportive at all" and a response of 5 indicated that they viewed their family supports and "very supportive." Demographic correlations in relation to the outcome variables of PTSD, PTG, and resiliency are listed in Table 3. 


\begin{tabular}{|c|c|c|c|c|c|c|c|c|c|c|c|c|c|c|c|c|}
\hline & PCL-5 & PTGI & BRS & $\begin{array}{l}\text { Time Since } \\
\text { Deployment }\end{array}$ & Age & Gender & $\begin{array}{l}\text { Number of } \\
\text { Deployments }\end{array}$ & Education & $\begin{array}{l}\text { Military } \\
\text { Grade }\end{array}$ & $\begin{array}{l}\text { Income } \\
\text { Level }\end{array}$ & Religiosity & TBI & $\begin{array}{l}\text { Chronic } \\
\text { Pain/ } \\
\text { Injury }\end{array}$ & $\begin{array}{l}\text { Social } \\
\text { Support }\end{array}$ & $\begin{array}{l}\text { Family } \\
\text { Support }\end{array}$ & $\begin{array}{l}\text { Mental } \\
\text { Health } \\
\text { Treatment }\end{array}$ \\
\hline PCL-5 & 1.00 & & & & & & & & & & & & & & & \\
\hline PTGI & -.117 & 1.00 & & & & & & & & & & & & & & \\
\hline BRS & $-.570 * *$ & $.259^{* *}$ & 1.00 & & & & & & & & & & & & & \\
\hline $\begin{array}{l}\text { Time Since } \\
\text { Deployment }\end{array}$ & .032 & .090 & $-.191 *$ & 1.00 & & & & & & & & & & & & \\
\hline Age & .037 & .116 & -.008 & $.307 * *$ & 1.00 & & & & & & & & & & & \\
\hline Gender & .072 & $.223^{*}$ & $-.207 *$ & $.259 * *$ & -.022 & 1.00 & & & & & & & & & & \\
\hline $\begin{array}{l}\text { Number of } \\
\text { Deployments }\end{array}$ & -.041 & -.009 & $.312 * *$ & $-.194 *$ & $.321 * *$ & -.125 & 1.00 & & & & & & & & & \\
\hline Education & $-.314 * *$ & .097 & $.196^{*}$ & .123 & $.258 * *$ & -.073 & .061 & 1.00 & & & & & & & & \\
\hline Military Grade & $-.281 * *$ & .042 & $.214^{*}$ & -.066 & $.437 * *$ & -.140 & $.187^{*}$ & $.571^{* *}$ & 1.00 & & & & & & & \\
\hline Income Level & $-.280 * *$ & .119 & $.237 * *$ & .044 & $.286^{* *}$ & -.017 & .104 & $.381 * *$ & $.566^{* *}$ & 1.00 & & & & & & \\
\hline Religiosity & .001 & $.316^{* *}$ & .078 & .029 & .156 & $.211^{*}$ & .049 & $.277 * *$ & $.242 * *$ & .105 & 1.00 & & & & & \\
\hline TBI & $-.285 * *$ & .018 & -.046 & $.234 * *$ & .079 & .135 & -.176 & $.257 * *$ & .084 & .035 & $.258 * *$ & 1.00 & & & & \\
\hline $\begin{array}{l}\text { Chronic } \\
\text { Pain/Injury }\end{array}$ & $-.366 * *$ & .134 & .163 & .058 & -.167 & .146 & $-.231 *$ & .096 & .059 & .041 & .061 & $.350 * *$ & 1.00 & & & \\
\hline Social Support & $-.279 * *$ & -.046 & .121 & -.066 & .026 & -.007 & .075 & $.212^{*}$ & $.185^{*}$ & .174 & $.253 * *$ & .086 & .094 & 1.00 & & \\
\hline Family Support & $-.226^{*}$ & -.083 & .043 & -.092 & .058 & -.080 & .114 & .172 & .147 & .096 & $.180^{*}$ & .132 & .172 & $.682 * *$ & 1.00 & \\
\hline $\begin{array}{l}\text { Mental Health } \\
\text { Treatment }\end{array}$ & $-.456 * *$ & -.041 & $.388 * *$ & $-.181^{*}$ & -.164 & $-.252 * *$ & -.001 & .025 & .039 & -.027 & -.073 & -.010 & .149 & .110 & .080 & 1.00 \\
\hline Mean & 2.60 & 2.45 & 3.49 & 5.91 & 34.08 & 1.19 & 3.22 & 4.42 & 7.02 & 3.13 & 2.67 & 1.64 & 1.55 & 3.71 & 3.98 & 1.39 \\
\hline $\mathrm{SD}$ & 1.01 & 1.17 & 0.96 & 1.987 & 9.165 & 0.393 & 1.354 & 1.633 & 4.772 & 1.310 & 1.363 & 0.498 & 0.500 & 1.153 & 1.225 & 0.489 \\
\hline Range & $\begin{array}{l}1.00- \\
4.70\end{array}$ & $\begin{array}{l}0.00- \\
5.00\end{array}$ & $\begin{array}{l}1.00- \\
5.00\end{array}$ & $1.00-8.00$ & $\begin{array}{l}22.00- \\
67.00\end{array}$ & $\begin{array}{l}1.00- \\
2.00\end{array}$ & $1.00-7.00$ & $1.00-8.00$ & $\begin{array}{l}2.00- \\
20.00\end{array}$ & $\begin{array}{l}1.00- \\
6.00\end{array}$ & $1.00-5.00$ & $\begin{array}{l}1.00- \\
3.00\end{array}$ & $\begin{array}{l}1.00- \\
2.00\end{array}$ & $\begin{array}{l}1.00- \\
5.00\end{array}$ & $\begin{array}{l}1.00- \\
5.00\end{array}$ & $1.00-2.00$ \\
\hline
\end{tabular}

* Correlation is significant at the 0.05 level (2-tailed)

** Correlation is significant at the 0.01 level (2-tailed)

Table 3. Descriptive statistics and Spearman correlations between demographic variables and outcome variables. 


\section{Internal Reliability of Measures}

Cronbach's Alpha was calculated for each scale to determine the internal consistency of the measures. The scales and their corresponding Cronbach's Alpha scores can be found in Table 1. All scales had Cronbach Alpha scores that were considered to be at least "acceptable", with most scales falling within the "excellent" range. None of the scale's alpha scores would have significantly benefitted from the deletion of any items, thus all scales were used as previously discussed in the methods section. The Posttraumatic Stress Disorder Checklist 5 (PCL-5), recently created to match DSM-5 diagnostic criteria for PTSD, had not previously been normed prior to the inclusion in this study. Both the PCL-M $(\alpha=0.96)$ and the PCL-5 $(\alpha=0.96)$ had similar, excellent internal reliability; as such, the newer PCL-5 was chosen for the remaining analyses.

Additionally, the Meaning in Life Questionnaire's (MLQ) two subscales were found to be significantly inversely correlated with different outcome measures. Due to this, the psychometric properties of the subscales were evaluated separately. Upon evaluating the subscales individually, the Cronbach's alpha for both the MLQ Search $(\alpha=0.90)$ and Presence $(\alpha=0.93)$ subscales were in the "excellent" range. This was an increase from the MLQ total scale, in which the Cronbach alpha score was in the "acceptable" range $(\alpha=0.69)$. Thus, for the remaining analyses, the MLQ was split into MLQ Presence and MLQ Search. By removing the MLQ total scale and splitting the MLQ into its subscales, all of the alpha scores for the measures in the analysis fell within the "good" to "excellent" range.

\section{Adaptions to the Scales}

As discussed in the previous section, the MLQ's two subscales were found to be significantly inversely related to one another and inversely correlated with different outcome 
measures. The "Presence" subscale was found to be significantly positively correlated with the PTGI $[r(131)=0.421, p<0.001]$ and negatively correlated with the PCL-5 $[r(132)=-0.579$, $p<0.001]$. The "Search" subscale was not significantly correlated with the PTGI $[r(131)=$ $0.109, p=0.215]$ but positively correlated with the PCL-5 $[r(132)=0.292, p=0.001]$. Thus, the MLQ subscales were split in the correlation matrix and evaluated separately within the model. A similar inverse relationship was found within the Finding and Found Meaning questions $r(139)=-0.273, p=0.001$ and as such, these variables were also split and evaluated separately within the following analyses and model. By splitting and adapting scales, the amount of power available to run the analysis was still acceptable based upon the recommended sample size (Kline, 2005; Loehlin, 2004; Tanaka, 1987).

As an additional adaptation to the scales used in this study, data transformation was necessary. In order to create standardized measurement of the scales, a mean score was calculated for each scale at the participant level. Thus, the scales were adapted from their traditional use. However, this transformation of the data did not alter the psychometric properties of the scales. Thus, all future references to the scales used in this analysis refer the mean score on each scale.

\section{Statistical Assumptions}

Prior to running any analyses related to the research questions, certain assumptions needed to be checked within the data set. Assumptions included univariate and multivariate normality, linearity, homoscedasticity, multicollinearity, regression outliers, and correct model specification.

In order to test for univariate normality within each scale, the mean, median, and mode were examined to determine if they overlapped within one standard deviation, and skewness (< 
2) and kurtosis $(<6)$ were also examined (See Table 4). All measures met these assumptions. Additionally, QQ plots, the Shapiro-Wilk test, and histograms were used to check for univariate normality. All analyses revealed a normally distributed sample for each scale measured. To determine multivariate normality, QQ plots and histograms of the measure's independent to dependent variable residual relationships were evaluated; all variables met multivariate normality criteria. 


\begin{tabular}{|c|c|c|c|c|c|c|c|c|c|c|c|c|}
\hline WAS $^{1}$ & AppVio & $\begin{array}{l}\text { MLQ } \\
\text { Presence }\end{array}$ & $\begin{array}{l}\text { MLQ } \\
\text { Search }\end{array}$ & PIL & $\begin{array}{l}\text { Finding } \\
\text { Meaning }\end{array}$ & $\begin{array}{l}\text { Found } \\
\text { Meaning }\end{array}$ & $\begin{array}{l}\text { IES-R } \\
\text { Avoidance }\end{array}$ & PCL-5 & PTGI & BRS & $\begin{array}{l}\text { Combat } \\
\text { Exposure }\end{array}$ & $\begin{array}{l}\# \\
\text { Deploy- } \\
\text { ments }\end{array}$ \\
\hline
\end{tabular}

\begin{tabular}{|c|c|c|c|c|c|c|c|c|c|c|c|c|c|}
\hline WAS & 1.00 & & & & & & & & & & & & \\
\hline AppVio & $.501 * *$ & 1.00 & & & & & & & & & & & \\
\hline MLQ Presence & $-.613 * *$ & $-.420 * *$ & 1.00 & & & & & & & & & & \\
\hline MLQ Search & $.197 *$ & $.277 * *$ & $-.284 * *$ & 1.00 & & & & & & & & & \\
\hline PIL & $-.712 * *$ & $-.429 * *$ & $.811 * *$ & $-.234 * *$ & 1.00 & & & & & & & & \\
\hline $\begin{array}{l}\text { Finding } \\
\text { Meaning }\end{array}$ & $.403 * *$ & $.591 * *$ & $-.353 * *$ & $.410 * *$ & $-.409 * *$ & 1.00 & & & & & & & \\
\hline Found Meaning & $-.430 * *$ & $-.401 * *$ & $.425 * *$ & $-.308 * *$ & $.460 * *$ & $-.273 * *$ & 1.00 & & & & & & \\
\hline $\begin{array}{l}\text { IES_R } \\
\text { Avoidance }\end{array}$ & $.515 * *$ & $.462 * *$ & $-.375 * *$ & .132 & $-.422 * *$ & $.352 * *$ & $-.330 * *$ & 1.00 & & & & & \\
\hline PCL-5 & $.639 * *$ & $.627 * *$ & $-.579 * *$ & $.292 * *$ & $-.624 * *$ & $.523 * *$ & $-.462 * *$ & $.695 * *$ & 1.00 & & & & \\
\hline PTGI & $-.279 * *$ & $.200 *$ & $.421 * *$ & .109 & $.372 * *$ & .107 & $.200 *$ & -.046 & -.117 & 1.00 & & & \\
\hline BRS & $-.547 * *$ & $-.347 * *$ & $.511 * *$ & $-.247 * *$ & $.620 * *$ & $-.399 * *$ & $.303 * *$ & $-.382 * *$ & $-.570 * *$ & $.259 * *$ & 1.00 & & \\
\hline $\begin{array}{l}\text { Combat } \\
\text { Exposure }\end{array}$ & .083 & $.229 *$ & -.148 & .064 & -.122 & .153 & -.103 & $.307 * *$ & $.366^{* *}$ & .042 & .009 & 1.00 & \\
\hline $\begin{array}{l}\text { \# of } \\
\text { Deployments }\end{array}$ & -.167 & .016 & .141 & -.049 & $.205^{*}$ & -.106 & .123 & .000 & -.041 & -.009 & $.312 * *$ & $.345 * *$ & 1.00 \\
\hline Mean & 2.80 & 2.49 & 4.68 & 4.54 & 3.54 & 2.53 & 2.40 & 1.26 & 2.60 & 2.45 & 3.49 & 10.42 & 3.21 \\
\hline SD & 0.47 & 0.77 & 1.61 & 1.46 & 0.77 & 1.03 & 1.08 & 0.93 & 1.01 & 1.17 & 0.96 & 4.35 & 1.35 \\
\hline Range & $\begin{array}{l}1.69- \\
3.81\end{array}$ & $\begin{array}{l}1.00- \\
4.00\end{array}$ & $\begin{array}{l}1.00- \\
7.00\end{array}$ & $\begin{array}{l}1.00- \\
7.00\end{array}$ & $\begin{array}{l}1.40- \\
4.95\end{array}$ & $\begin{array}{l}1.00- \\
4.00\end{array}$ & $\begin{array}{l}1.00- \\
4.00\end{array}$ & $\begin{array}{l}0.00- \\
3.75\end{array}$ & $\begin{array}{l}1.00- \\
4.70\end{array}$ & $\begin{array}{l}0.00- \\
5.00\end{array}$ & $\begin{array}{l}1.00- \\
5.00\end{array}$ & $\begin{array}{l}1.00- \\
18.00\end{array}$ & $\begin{array}{l}1.00- \\
7.00\end{array}$ \\
\hline Skew & 0.09 & -0.10 & -0.42 & -0.43 & -0.24 & 0.07 & 0.19 & 0.32 & .273 & 0.06 & -0.62 & -0.21 & 1.50 \\
\hline Kurtosis & -0.64 & -0.81 & -0.71 & -0.33 & -0.50 & -1.17 & -1.21 & -0.81 & -0.99 & -0.56 & -0.13 & -1.16 & 1.89 \\
\hline
\end{tabular}

* Correlation is significant at the 0.05 level (2-tailed)

** Correlation is significant at the 0.01 level (2-tailed)

${ }^{1}$ The World Assumptions Scale was initially reverse coded, to be included in the "Violation of World Beliefs" latent variable

Table 4. Correlation Matrix for Variables Included within the Model 
Scatter plots of the bivariate regression residuals including Mahalanobis Test, Cook's Distance, and standard residual scores were used to check for a linear relationship between independent and dependent variables within the dataset. The standard cutoff of greater than three was used for the standard residual. A cutoff of greater than one for Cook's distance was used. According to Barnett and Lewis' (1978) table, with one predictor and a sample size of greater than 100, the cutoff score for determining the Mahalanobis test was set at greater than 3.6. No independent-dependent variable was above the cutoff for having a nonlinear relationship.

The homoscedasticity assumption was evaluated by checking for a consistent residual spread; data met this assumption. Regression outliers in the areas of leverage, discrepancy, and influence of the residuals were also evaluated. Using the cutoff of three standard deviations to determine a discrepancy-related outlier, and the cutoff of greater than $.0336(4 / \mathrm{n})$ as the influence-related outliers; no outliers were found to significantly influence the data set (Tabachnick \& Fidell, 2012).

The multicollinearity of the relationships was checked using the tolerance and variance inflation factor related to the predictors in the model. Tolerance is a measure that ranges from zero to one, with scores closer to one being considered better. Variance inflation is considered to have occurred if scores are greater than or equal to ten. No extreme scores for tolerance or variance inflation were found.

Correct model specification was utilized, as an initial first step to ensure bivariate relationships existed prior to model inclusion. Pearson correlations were used for this initial examination; correlations that were not significant $(\mathrm{p}<0.05)$ were then excluded from the model. Significant correlations of the measures can be found on Table 4. Specifically of note, the covariate of sex was not found to be significantly correlated with the measure of PTSD $[r(122)$ 
$=0.072, p=0.430]$ and as such was not included in the correlation matrix and was removed from the proposed model. Finally, the measure of combat exposure was significantly correlated with $\operatorname{PTSD}[r(122)=0.366, p<0.001]$ during the correlational analysis; whereas number of deployments was not statistically significantly related to PTSD $[r(119)=-0.041, \mathrm{p}=0.657]$ but was found to be significantly correlated with resiliency $[r(119)=0.312, p=0.001]$. As such, combat exposure was included as a covariate in the following proposed model and number of deployments was only used as a covariate for resiliency.

\section{Structural Equation Modeling (SEM) Analysis}

After meeting statistical assumptions, the SEM analysis was conducted. However, as previously discussed, the original hypothesized model was revised based upon correct model specification criteria. Specifically, sex was removed as a covariate for PTSD and combat exposure was added as a covariate for PTSD. The number of deployments was not used as a covariate for all outcome measures but was instead only used as a covariate for the resiliency outcome. Additionally, the finding meaning measure and the Meaning in Life Questionnaire subscale for Search for Meaning were removed from the "Meaning Made" construct and combined to create a new path titled "Continuing to Make Meaning." Thus, the model that was tested in the first SEM can be found in Figure 4. 


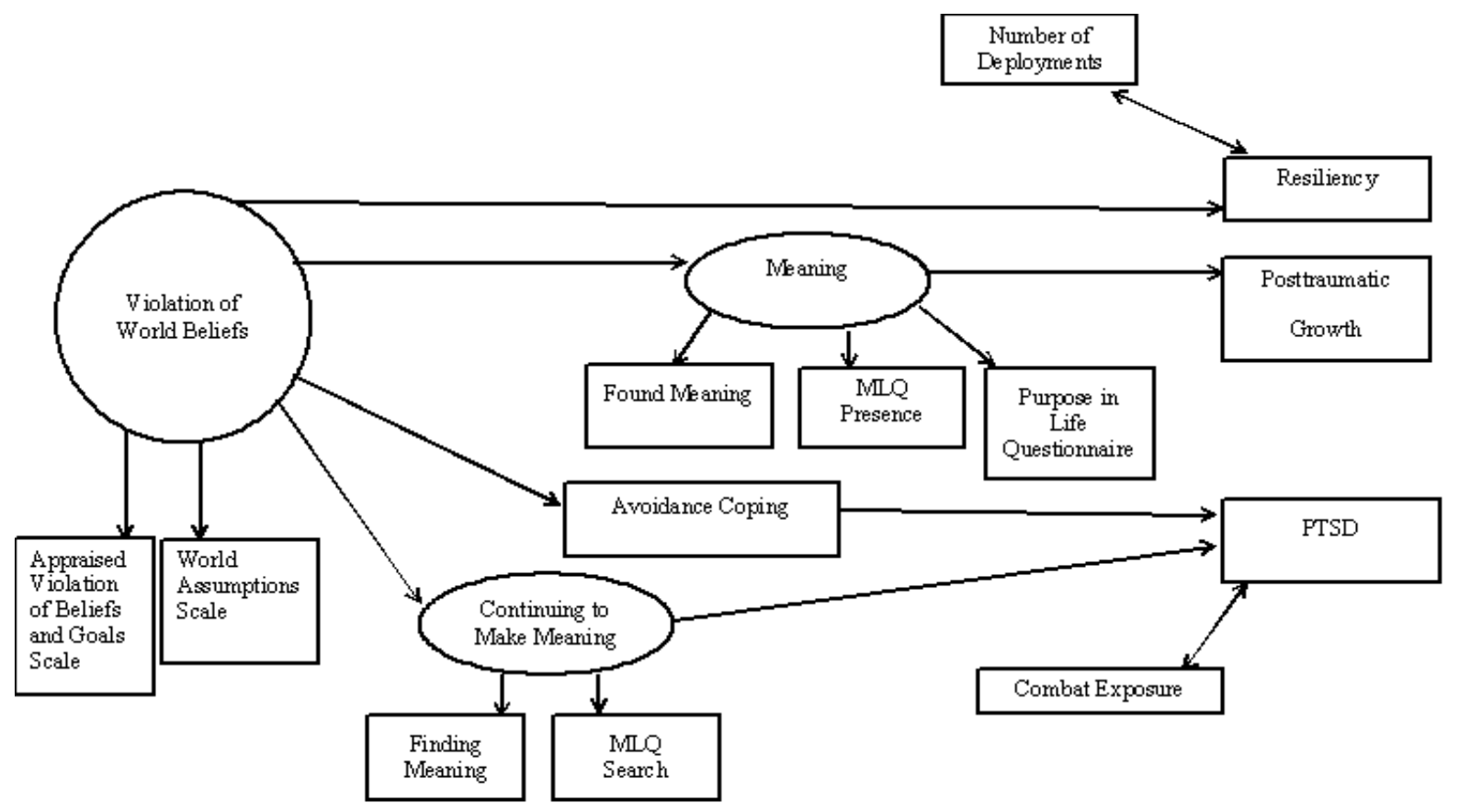

Figure 4. Hypothesized Model (after correct model specification).

Upon using the Proc Calis function within the statistical program SAS 9.3 (SAS Institute, 2013), the revised hypothesized model was tested. The specific measurement between each variable can be found in Figure 5. All of the model fit indices that were evaluated can be found in Table 5, with a comparison to the final model. Goodness of fit statistics indicated a model that was an adequate fit, but one that could be improved. For example, for models with about 75 to 200 cases, the Chi-Square test is a reasonable measure of overall model fit, utilizing reverse hypothesis testing. The first hypothesized model had a significant $p$-value, $\chi^{2}(60)=168.56$, $p<0.001$, which indicates that the model does not fit the data well. However, this type of goodness of fit test is often over-powered, so that even small discrepancies in the data lead to significant $p$-values; thus, other goodness of fit measures are also evaluated. 


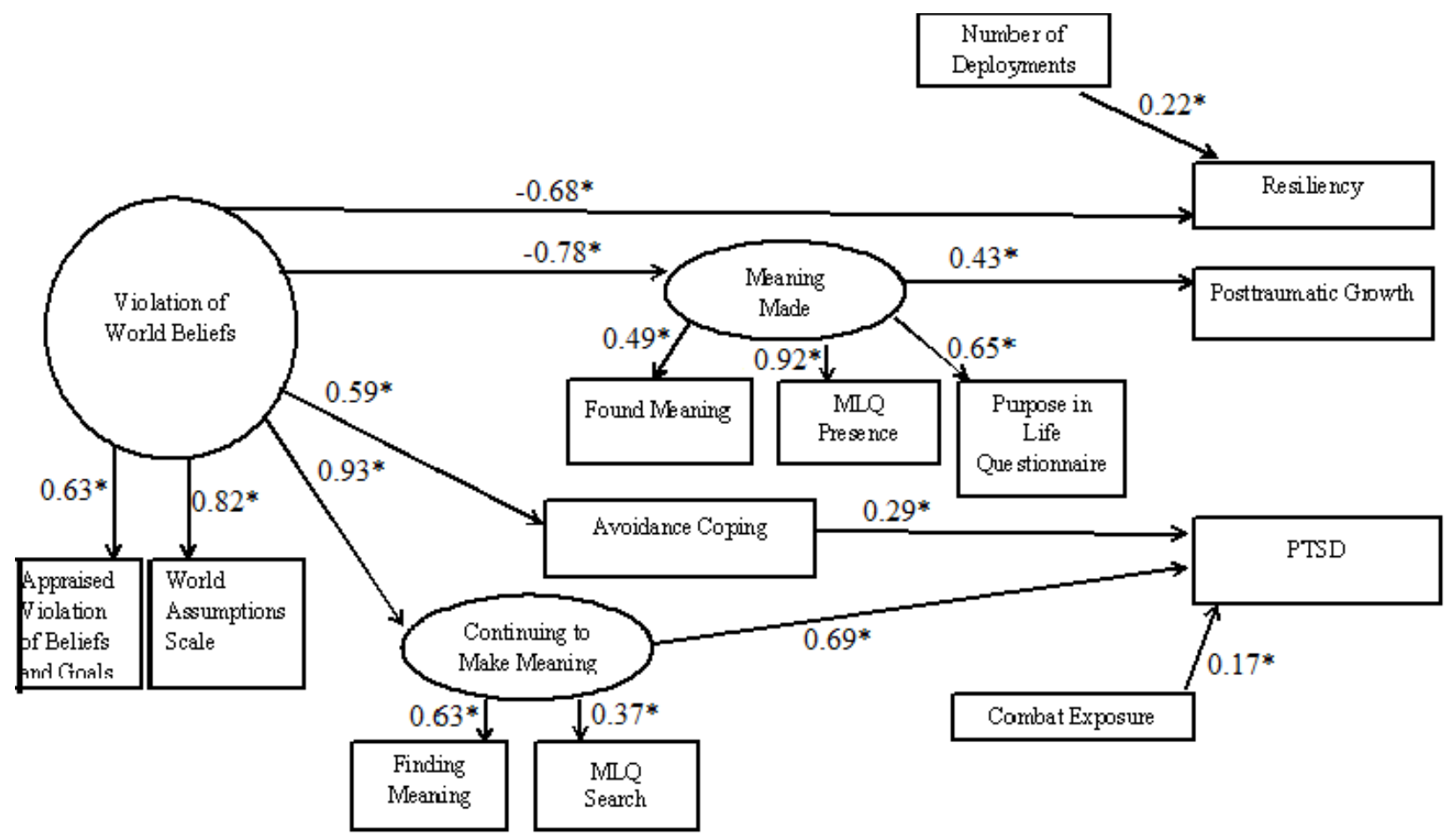

Figure 5. Hypothesized Model with standardized beta coefficients.

Note. * indicates beta coefficients that are significant at the $p<0.05$ level.

Fit Index Target Score
Hypothesized Model

\section{Best Fitting Model}

\begin{tabular}{lccc}
\hline AIC & $\begin{array}{c}\text { Smaller is better for } \\
\text { nested models } \\
\text { Smaller is better for } \\
\text { nested models }\end{array}$ & $4794.45^{*}$ & $2822.52^{*}$ \\
BIC & $\mathrm{p}>0.05$ & $\chi^{2}(60)=168.56, \mathrm{p}<0.001$ & $2887.10^{*}$ \\
$\chi^{2}$ & $<0.08$ & 0.11 & $\chi^{2}(24)=71.71, \mathrm{p}<0.0001$ \\
SRMR & $>0.90$ & 0.82 & 0.08 \\
GFI & $>0.90$ & 0.73 & 0.88 \\
AGFI & $<0.08$ & $0.11(0.09-0.13)$ & 0.78 \\
RMSEA & $>0.90$ & 0.86 & $0.11(0.08-0.14)$ \\
CFI & $>0.90$ & 0.82 & 0.92 \\
NNFI & & & 0.89 \\
\hline
\end{tabular}

Table 5. Fit Indices of the Models.

Note. * indicates that the models listed are not nested and as such the AIC and the BIC fix indexes cannot be compared. 
The next measure of fit examined was the Standardized Root Mean Square Residual (SRMR), an absolute measure of fit and is defined as the standardized difference between the observed correlation and the predicted correlation, with a value of zero indicating perfect fit. The measure is positively biased and that bias is greater for small sample sizes with low degrees of freedom. A value less than 0.08 is generally considered a good fit (Hu \& Bentler, 1999). The SRMR for Figure 5 was equal to 0.11.

The Goodness of Fit Statistic (GFI) and the Adjusted Goodness of Fit Statistic (AGFI) are additional measures of fit. These measures can often be affected by sample size and thus may not be a wholly accurate measure (Sharma, Mukherjee, Kumar, \& Dillon, 2005). A value greater than 0.90 for both GFI and AGFI is considered a good fit. For this model, the GFI=0.82 and the $\mathrm{AGFI}=0.73$.

The Root Mean Square Error of Approximation (RMSEA) is one of the most popular measures of fit. The RMSEA adjusts for model parsimony (number of variables added to the model). It is suggested that scores of 0.01 (excellent), 0.05 (good), and 0.08 (mediocre) be used as cutoffs to indicate fit (MacCallum, Browne \& Sugawara, 1996). For the hypothesized model, the RMSEA=0.11. A 90\% confidence interval can be calculated for RMSEA. The width of the confidence interval can also be very informative about the precision in the RMSEA estimate. The confidence interval for the hypothesized model did not include the lowest RMSEA cut-off value $(0.09-0.13)$.

The Bentler Comparative Fit Index (CFI) and the Bentler-Bonett Non-Normed Index (NNFI) are additional measures of fit that are directly based on the non-centrality measure. For the CFI and NNFI, a score of greater than 0.90 indicates a good fit. For the hypothesized model the $\mathrm{CFI}=0.86$ and the $\mathrm{NNFI}=0.82$. 
Thus, by reviewing the recommended scores for a good fitting model, it appears that Figure 5 is approaching being an adequate fit as a model but not yet ideal (Bollen, 1989; Loelin, 2004; Byrne, 1994). Due to this, additional models were tested using a Step Through statistical process in which the direct effects were tested first and the indirect effects were then analyzed based on the strength of the relationships. The results of this analysis can be found in Figure 6 .

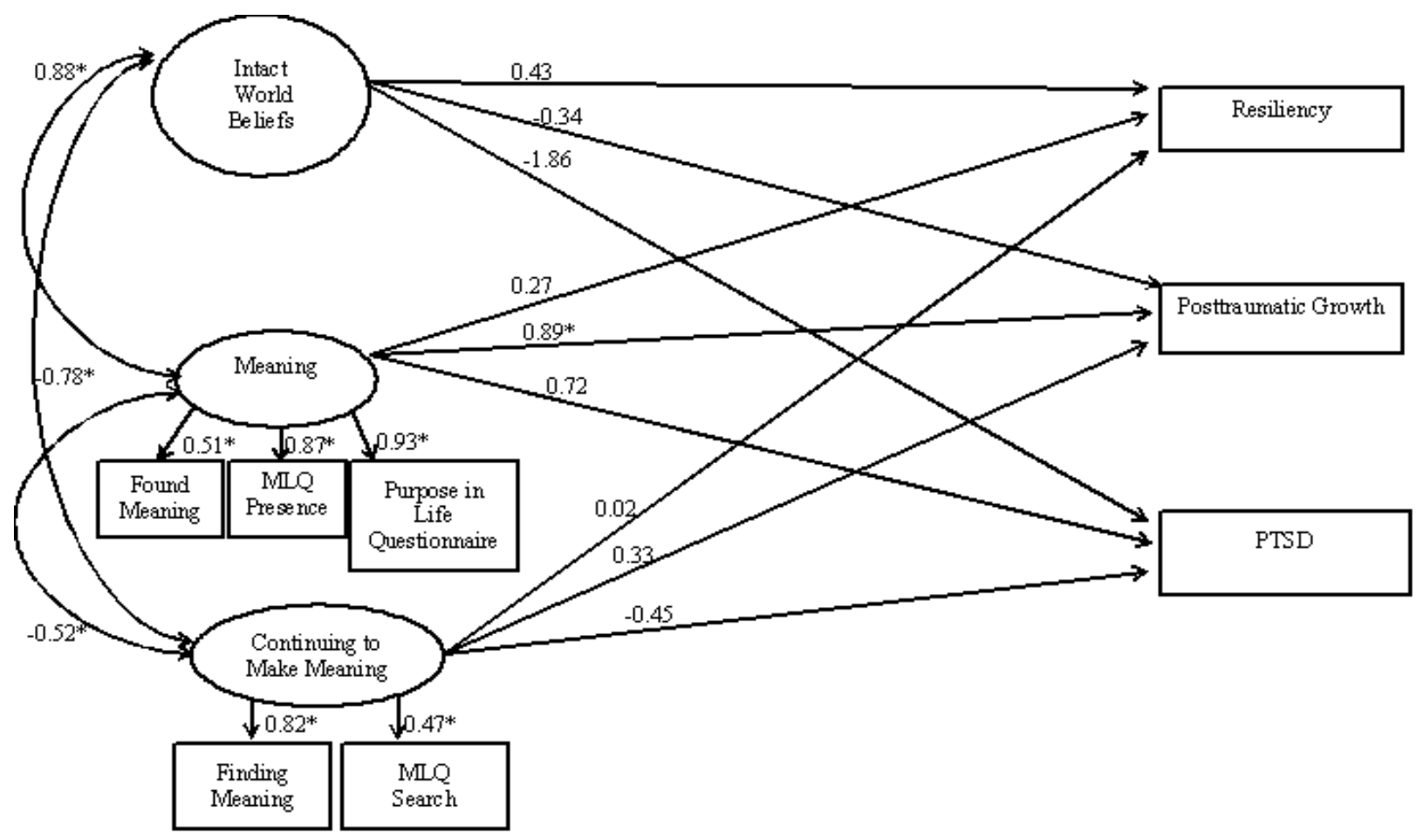

Figure 6. Direct Effects of Variables with standardized beta coefficients.

Note. * indicates beta coefficients that are significant at the $p<0.05$ level.

Upon evaluation of the direct effects, the "Continuing to Make Meaning" path was removed from the analysis. Additional alterations to the model were examined to determine the best fitting model. By removing both the covariates of number of deployments and combat exposure, the model was strengthened.

Initially, combat exposure and number of deployments were hypothesized as covariates to the model. Although there was a significant correlation between combat exposure and PTSD 
$(r=.37, \mathrm{p}<0.01)$; as well as between number of deployments and resiliency $(r=.31, \mathrm{p}<0.01)$, the associations were weak and did not significantly improve the fit of the model. In fact, by removing both covariates, the model was strengthened. With the removal of the covariates, the AIC decreased from 4211.54 to 2822.5 and the BIC decreased from 4298.67to 2887.10. The AIC and the BIC are able to be compared due to being a nested model of one another and smaller numbers indicate a better fitting model. When including the covariates of combat exposure and number of deployments, $\chi^{2}(38)=92.33, \mathrm{p}<0.0001, \mathrm{SRMR}=0.08, \mathrm{GFI}=0.87, \mathrm{AGFI}=0.78$, RMSEA $=0.09(0.07-0.12) . \mathrm{CFI}=0.92, \mathrm{NNFI}=0.88$. As can be seen in Table 5 , when compared to the final model, the inclusion of the covariates does not improve the model.

Other demographics were also included in the model to determine if they account for any additional variance in the model. The correlated demographic variables of education, military grade, income level, traumatic brain injury, social support, family support, receiving mental health treatment, degree of religiosity/spirituality, time since deployment, and gender were examined to the outcome variables. By including these covariates, there was not a significant improvement in the goodness of fit of the model. Conversely, by including each covariate separately, the final model's fit was decreased. See Tables 6, 7, and 8 for specific fit statistics associated with the inclusion of each demographic variable. 


\begin{tabular}{|c|c|c|c|c|c|c|c|c|c|c|}
\hline $\begin{array}{l}\text { Fit } \\
\text { Index }\end{array}$ & Education & $\begin{array}{l}\text { Military } \\
\text { Grade }\end{array}$ & $\begin{array}{l}\text { Income } \\
\text { Level }\end{array}$ & TBI & $\begin{array}{l}\text { Social } \\
\text { Support }\end{array}$ & $\begin{array}{l}\text { Family } \\
\text { Support }\end{array}$ & $\begin{array}{l}\text { Mental } \\
\text { Health } \\
\text { Treatment }\end{array}$ & Religiosity & $\begin{array}{l}\text { Time Since } \\
\text { Deployment }\end{array}$ & Gender \\
\hline AIC & 3270.73 & 3534.52 & 3221.68 & 2981.09 & 3195.57 & 3213.29 & 2968.03 & 3242.29 & 3520.36 & 2940.17 \\
\hline BIC & 3344.53 & 3608.33 & 3319.48 & 3054.89 & 3269.38 & 3287.10 & 3041.84 & 3316.10 & 3595.05 & 3013.98 \\
\hline$\chi^{2}(31)$ & $80.18^{*}$ & $87.24 *$ & $94.11 *$ & $88.93^{*}$ & $86.06^{*}$ & $85.21 *$ & $82.13^{*}$ & $91.49 *$ & $79.22 *$ & $90.71 *$ \\
\hline SRMR & 0.09 & 0.08 & 0.09 & 0.08 & 0.08 & 0.08 & 0.08 & 0.10 & 0.08 & 0.09 \\
\hline GFI & 0.88 & 0.88 & 0.87 & 0.87 & 0.88 & 0.88 & 0.88 & 0.86 & 0.88 & 0.86 \\
\hline AGFI & 0.80 & 0.79 & 0.78 & 0.77 & 0.78 & 0.78 & 0.78 & 0.75 & 0.79 & 0.76 \\
\hline RMSEA & 0.10 & 0.12 & 0.11 & 0.11 & 0.11 & 0.10 & 0.10 & 0.11 & 0.10 & 0.11 \\
\hline CFI & 0.92 & 0.91 & 0.90 & 0.91 & 0.92 & 0.92 & 0.92 & 0.91 & 0.92 & 0.91 \\
\hline NNFI & 0.89 & 0.87 & 0.86 & 0.87 & 0.88 & 0.88 & 0.89 & 0.86 & 0.89 & 0.87 \\
\hline
\end{tabular}

Note. ${ }^{*}$ Chi-square is significant at the $\mathrm{p}<0.001$ level (2-tailed)

Table 6. Fit Indices of the Model with the inclusion of demographic variables as a covariate for the PTSD outcome. 


\begin{tabular}{lll}
\hline $\begin{array}{l}\text { Fit } \\
\text { Index }\end{array}$ & Religiosity & Gender \\
\hline AIC & 3235.93 & 2934.37 \\
BIC & 3309.73 & 3008.17 \\
$\chi^{2}(31)$ & $85.13^{*}$ & $84.90^{*}$ \\
SRMR & 0.09 & 0.08 \\
GFI & 0.88 & 0.88 \\
AGFI & 0.78 & 0.79 \\
RMSEA & 0.10 & 0.10 \\
CFI & 0.92 & 0.92 \\
NNFI & 0.88 & 0.88 \\
\hline
\end{tabular}

Note. $*$ indicates that the chi-square is significant at the $\mathrm{p}<0.001$ level (2-tailed).

Table 7. Fit Indices of the Model with the inclusion of demographic variables as a covariate for the Posttraumatic Growth outcome. 


\begin{tabular}{lllllll}
\hline $\begin{array}{l}\text { Fit } \\
\text { Index }\end{array}$ & Education & $\begin{array}{l}\text { Military } \\
\text { Grade }\end{array}$ & $\begin{array}{l}\text { Income } \\
\text { Level }\end{array}$ & $\begin{array}{l}\text { Mental } \\
\text { Health } \\
\text { Treatment }\end{array}$ & $\begin{array}{l}\text { Time Since } \\
\text { Deployment }\end{array}$ & Gender \\
\hline AIC & 3270.28 & 3534.61 & 3222.7007 & 2968.09 & 3521.42 & 2940.37 \\
BIC & 3344.09 & 3608.41 & 3296.5049 & 3041.89 & 3596.11 & 3014.17 \\
$\chi^{2}(31)$ & $79.73^{*}$ & $87.32^{*}$ & $95.13^{*}$ & $82.18^{*}$ & $80.28^{*}$ & $90.90^{*}$ \\
SRMR & 0.08 & 0.08 & 0.09 & 0.08 & 0.08 & 0.09 \\
GFI & 0.89 & 0.88 & 0.87 & 0.87 & 0.88 & 0.86 \\
AGFI & 0.80 & 0.79 & 0.77 & 0.78 & 0.79 & 0.76 \\
RMSEA & 0.10 & 0.12 & 0.11 & 0.10 & 0.10 & 0.11 \\
CFI & 0.92 & 0.91 & 0.90 & 0.92 & 0.92 & 0.91 \\
NNFI & 0.89 & 0.87 & 0.86 & 0.89 & 0.89 & 0.87 \\
\hline
\end{tabular}

Note. $*$ indicates that chi-square is significant at the $\mathrm{p}<0.001$ level (2-tailed)

Table 8. Fit Indices of the Model with the inclusion of demographic variables as a covariate for the resiliency outcome. 
Finally, the endogenous variable of "violation of world beliefs" was recoded and changed to "intact world beliefs." This was done in order to simplify the discussion related to the variable. It was completed by reverse coding the Violation of Beliefs and Goals Scale instead of the World Assumptions Scale as previously planned. By reverse coding this latent variable, there was no statistical change to the model.

Eleven separate models were analyzed. The best fitting model was determined by alignment with both theoretical and statistical assumptions. Upon completed exploration of the data, the model determined to be the best fitting model is shown (with the strength of the associations) in Figure 7. The $\chi^{2}(24)=71.71, p>.0001$ indicating a better fit than the original model (although still significant). The SRMR $=0.08$, indicating a good fit. The GFI $=0.88$ and the AGFI $=0.78$, these scores are better than the original model and an adequate fit; however still below desired cut-offs. The RMSEA $=0.11,90 \%$ CI: $0.08-0.14$; due to this confidence interval including the cutoff of 0.08, this is also considered a mediocre fit (Bollen, 1989; Loelin, 2004; Byrne, 1994). Finally, the CFI 0.92 , which is a good fit and the NNFI $=0.89$, which is an adequate fit. The comparison between the fit indices can be found in Table 5. Evaluation of the specific paths resulting from this model will be expanded upon in further detail in the following chapter. 


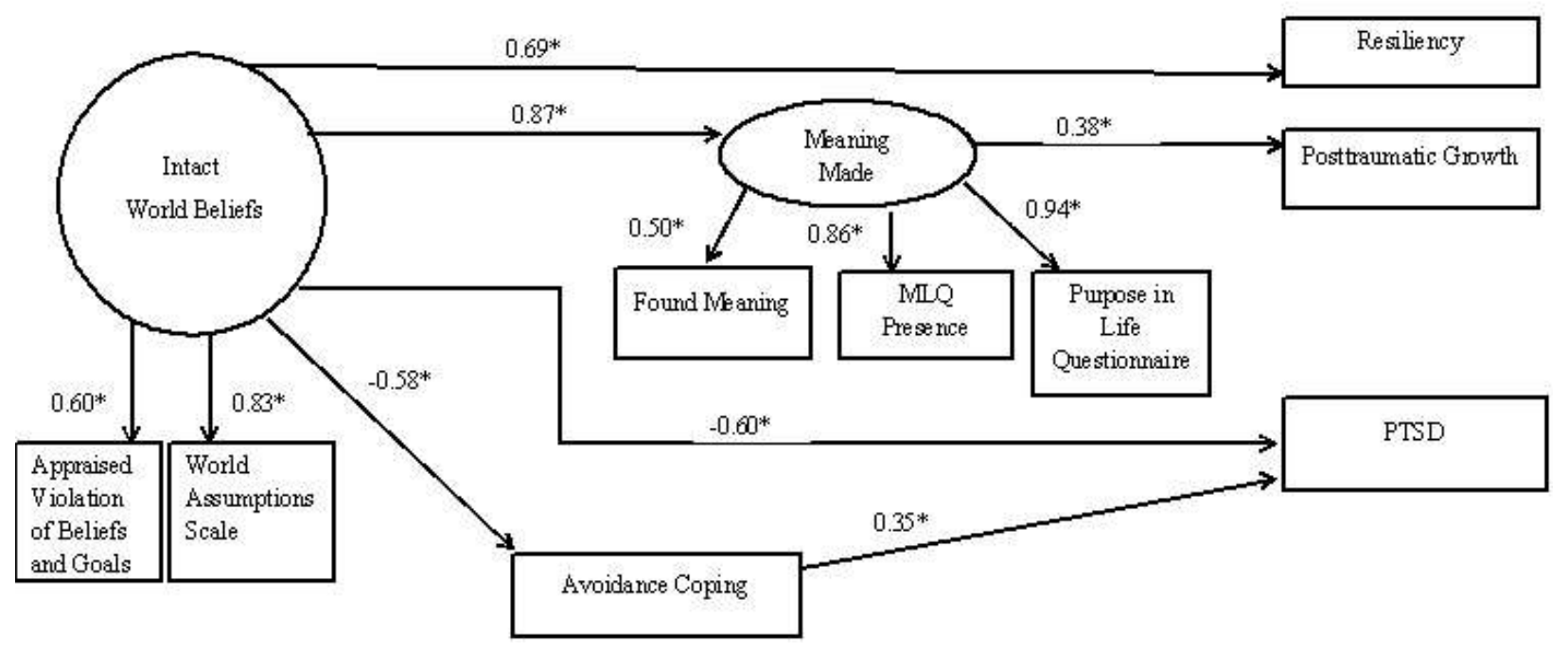

Figure 7. Best Fitting Model with standardized beta coefficient estimates.

Note. $*$ indicates beta coefficients that are significant at the $p<0.05$ level. 


\section{CHAPTER 5: INTERPRETATIONS, CONCLUSIONS, AND RECOMMENDATIONS}

Through the use of Structural Equation Modeling (SEM), the hypothesized path was created using meaning making as the determining factor in the trauma trajectory. Within this model, the data provide some support for the theory that meaning can drive the trauma trajectory in combat trauma (Larner \& Blow, 2011). The model indicates that following a stressful life event, if an individual's beliefs remain intact or does not experience a shattering of their world beliefs (a high score on the "intact world beliefs" variable), they are likely to be resilient. However, if an individual does experience a shattering of his or her world beliefs (a low score on "intact world beliefs"), this process alone is enough to make it likely that an individual will report symptoms of Posttraumatic Stress Disorder (PTSD). Upon experiencing a shattering of world beliefs, if the individual engages in avoidance coping (a high score on the "avoidance coping" variable), he or she is also more likely to experience PTSD. However, the higher the level of intact world beliefs the individual reports, the more likely that they are to report having made meaning from the event (a high score on "meaning made"). Additionally, if an individual scores highly on intact world beliefs and meaning make, he or she is also more likely to report an experience of Posttraumatic Growth (PTG).

A key difference between the findings of this study and the study that inspired it (Larner \& Blow, 2011) is that a shattering of world beliefs did not lead to meaning making in the current study. Evaluating this finding from a pragmatic angle, it is possible that after an individual makes meaning, they no longer report a violation of world beliefs due to the dissonance being resolved. This will be discussed further in the limitations section.

The Larner and Blow (2011) model also differed from the current model in that it looked at global meanings and appraised meanings separately prior to deployment and then examined if 
the appraised meaning violated the global meaning during deployment. Due to the retrospective nature of this study, the use of intact and/or violation of world beliefs was considered to be analogous to Larner and Blow's global versus appraised meaning variable. It is unclear if there would be a significant difference if the variable had been measured in a different manner, but it is this author's opinion that it would have strengthened the model.

Additionally, the outcomes included in the current study were PTSD, PTG, and resiliency; whereas the outcomes in the Larner and Blow (2011) model are "constructive, coherent meaning made" and "destructive, self-critical meanings made." The second outcome considered by Larner and Blow included PTSD, depression, and suicidality. In order to limit the scope of the present study, only PTSD was examined. Larner and Blow also conceptualized resiliency and PTG as being similar to each other and did not differentiate between the two outcomes.

The current study builds and refines the current theories that exist. First and foremost, the model supports the idea that meaning making is an important aspect for an individual that experiences a stressful life event. Secondly, resiliency and PTG are clearly different outcomes and should not be considered analogous, as is often done in the psychological community. Resiliency and PTG have different predictor variables and different demographic factors associated with each (Calhoun \& Tedeschi, 2006; Reivich, 2003). It would be important for any clinician or researcher to recognize and differentiate the often subtle differences that each outcome possesses.

Additionally, some variables did not make it into the model. The variable of "searching for meaning" was included in the model that was first tested. In initial model tests, the variable of "searching for meaning" predicted a large variance in the outcome variable of PTSD. 
However, by using overall goodness of fit statistics, it was determined that the model was stronger with the exclusion of the variable. This may indicate that continuing to search for meaning is an integral part of PTSD and/or experiencing a shattering of world beliefs but itself is not predictive of the presence of PTSD. In other words, searching for meaning may occur if there is a shattering of world beliefs, but this process itself is not uniquely different from the occurrence of PTSD.

Combat exposure and number of deployments were removed from the model, and the model fit increased by this removal. This may indicate that although there is some association between the number of deployments and combat exposure that military members experience and the outcome variables of resiliency and PTSD respectively, the processes of resiliency and PTSD are independent outcomes that are much more affected by maintenance of intact world beliefs or the shattering of world beliefs. Correlated demographic variables were also examined to the outcome variables and found to decrease the model fit. Similarly to the hypothesized covariates of number of deployments and combat exposure, this may indicate that although the covariates account for some variability within the model, the variance within PTSD, PTG, and resiliency are better accounted for by the intact or shattering of world beliefs and meaning making.

Gender was excluded as a covariate from the model due to not significantly improving the model fit. There are many possible explanations for why PTSD was not strongly predicted by gender in this model when previous literature suggests a strong link between the two. The most likely cause for the reduction of gender's strength in this model is due to the relatively small representation of women within the sample. This becomes an even more crucial aspect to consider given that 44 participants were included in the analysis who did not report their gender. 
It appears there is far more that we do not know related to the influence of the respondent's gender.

Similarly, the number of individuals included in the study that reported seeking out mental health treatment following combat is high. Over $60 \%$ of the respondents in this study reported receiving mental health treatment upon returning from combat. It is possible that this skewed the results and increased the reported level of psychopathology in this study. The pitfalls of a convenience sample are discussed in further detail in the limitations section.

The final model determined to be the best fit for the data is considered to be statistically "adequate", but not "good" or "excellent." There are many reasons why this could occur, and those reasons will be further outlined within the limitations section. However, as this was a novel study, the results indicate that this is a good starting place for future research. Additionally, the results supported the model initially proposed by Larner and Blow (2011). The clinical implications of this study will be examined in the following section.

\section{Clinical Implications}

The most important clinical implication of this research study is that it support for the Park (2008) and Larner and Blow (2011) hypothesis, which states that meaning making drives trauma trajectories. Both the Larner and Blow (2011) model and the Park (2008) model are supported by these findings. The Larner and Blow (2011) theory would indicate that these findings would likely also extend beyond the combat veteran population; however, additional studies are necessary to validate this claim.

Strong linkages between meaning making and the posttraumatic trajectories of PTSD, PTG, and resiliency, could impact trauma work with combat veterans. In the future, individuals preparing for deployment could engage in psychoeducation about violation of global meanings 
and be given assistance in reappraisal of discrepant meanings post-deployment. Clinicians would also have a better grasp on how to focus on the post-deployment soldier's difficulties of readjusting after a trauma. Unfortunately, readjustment theories are better developed than readjustment research in the PTG and meaning-making areas (Park, 2010). It is still unknown if training can impact or encourage PTG (Tedschi \& McNally, 2011). It is a growing hope that specific interventions will be able to encourage PTG, but until further studies are conducted, the answer to this critical question remains an unknown.

An interesting clinical implication to this study would be the increased use of psychologists imbedded with combat troops. The military has already begun to implement use of psychologists upon military members return from the front lines. Future studies could look at the benefit of having the ability for military members to meet with a psychologist immediately upon experiencing a stressful combat situation. The results of this study suggest that these meetings could be beneficial for troops. Additionally, considering the cost that the Department of Defense spends per individual diagnosed with PTSD, the financial savings of immediate treatment could be astronomical. Nonetheless, future studies are necessary.

This study adds to the body of research supporting the use of Cognitive Processing Therapy (CPT) for combat veterans. The goal of CPT is for individuals with PTSD to examine the meaning that they have ascribed to the traumatic event, identify specific beliefs that are keeping them "stuck" in their PTSD, and replace with beliefs that are more balanced and functional within their lives. The process of CPT also discourages avoidance. Conceptually, the model that was found within this study supports the theory behind CPT.

There is still much variability within the model that was not accounted for by the predictor variables. Because the model continues to have unexplained variability, there is not a 
direct link between this research and clinical implications that can be immediately beneficial. However, the evidence does indicate that there are strong relationships among meaning making, PTG, PTSD, and resiliency (see Figure 6). A discussion of the limitations that may have had an effect on the outcomes is discussed within the next section.

\section{Limitations}

Although the final model in this study was considered to be an "adequate" fit, it is quite possible that modifications to this study may increase the goodness of fit to the model. Limitations encountered within the study will be examined in this section. Specifically, the study's sample was a sample of convenience. Thus, it is possible that the individuals who responded to this study are not a representative of most combat veterans. The sample included a large standard deviation for age, a large variance in rank, and multiple combat deployment sites. This created a heterogeneous group, and because of this, it is difficult to determine which factors may be influencing the outcome variables. For example, there were nine company grade officers (O-3) and 39 mid-level enlisted ranked military members (E-5) included within the study. Thus, there may not have been enough power within each military rank group to detect a significant difference between rank and any of the outcome variables. This concern extends to many other demographic variables, such as time since deployment, age, and sex.

Another potential limitation of this study involve its retrospective and self-report design. Participants in the study were asked to remember their beliefs before and after combat. They were also asked about their world assumptions at the time of completing the survey. If the proximity of the trauma was far from the time that the participant filled out the survey, it is possible that the individuals did not remember their previous beliefs. Additionally, it is possible 
that, similar to the theory of cognitive dissonance, individuals may have incorrectly reported their current belief system as being static across their lifespan.

Another limitation is that the meaning making assessments used in this study had a positive bias. The assessments asked the participants to rate their experiences on a Likert-type scale from "no change" in their life meanings to "much positive change" in their life meanings (Park et al., 2008). This leads to the question of whether meaning made is only complete if the outcome is positive. It is unknown whether an individual that ascribes a negative meaning to their experience and the world would also follow the same trajectories of PTSD versus PTG. For example, an individual may create the negative meaning that the world as a whole is an unsafe and dangerous place. If negative meaning making followed the same trajectory, it would be hypothesized that the individual would be more likely to experience PTG than if no meaning was made. This outcome appears to be counterintuitive but it is yet unknown how the current model would differ if making a negative meaning was also included in the model.

Similarly, it is possible that the measures used did not include all of the possible meanings an individual could make following a stressful life event. Or conversely, that an individual's self-report was affected by the types of meaning included within the measures. For example, a participant who completed the study contacted the author concerned that his atheism made it difficult for him to respond to certain questions related to his combat experience and an increase in belief in a higher power. Many measures of PTG have religious undertones, and for individuals who do not believe in a higher power, the measures may inappropriately skew their results.

Finally, in a recent article by Heintzelman and King (2014), the Purpose in Life and the Meaning in Life Questionnaires were evaluated. The authors concluded from their meta-analysis 
that most individuals rate their meaning in life as higher than average. They explored the reasoning for these skewed results through the lens of an individual positive illusion and a positive response bias. Interestingly, they also explored the idea that individuals may rate their lives as meaningful because individuals are unaware of the scholarly definition of the construct of meaning. Additionally, if individuals rate their meaning and purpose in life as high on average, it is possible that there is not enough variability within the scores to find the individuals who are struggling within this area but may still have scores that are in the average to above average range. Thus, systematic error to the measures used is a possible limitation to this study. In the next section, the strengths of the study and suggestions for future research are examined.

\section{Strengths}

The study took convoluted complex topic and an attempt was made to map the process. The study adequately supported current theories that exist as well as created a clear line for future research in the area. This study was the first known research project of its kind to determine the trauma trajectory in combat veterans utilizing meaning making and a predictive variable. Additionally, this study is on the cutting edge of hot topics for the status quo: veteran issues, positive psychology, and structural equation modeling are all areas that have begun to garner much attention recently. By attempting to incorporate all of these topics, this study demonstrates the zeitgeist of psychology.

\section{Future Directions}

Many limitations to the current study were examined in the previous section. It is believed that by working to eliminate some of these limitations, the theory in this area can be advanced. Thus, future studies should concentrate on the longitudinal exploration of meaning making. Longitudinal studies are needed to measure meaning making from a non-retrospective 
point of view. Unlike many other types of stressful experiences that are unexpected, it is highly likely that military personnel who prepare for deployment will be put in high stress situations. This allows for a research study to have pre- and post- deployment measures that can adequately be used to validate or repudiate this model.

Future studies could also include a qualitative study defining specific types of meanings that individuals make following a stressful life event. Additionally, mixed method studies could explore types of meanings that individuals make and their correlation to specific outcomes. Another suggestion for future studies includes using a very homogenous sample to reduce potential variance within the model. Finally, creating a study that explores negative meaning making as well as positive meaning making would be beneficial. Needless to say, this is a timely topic with many areas in need of future research.

\section{Conclusion}

The results of this study indicate that there is likely a strong link between an individual's world beliefs, how he or she makes meaning following a stressful life event, and the outcome variables of PTSD, PTG, and resiliency. Although the results of this study indicate a model that could continue to be strengthened by additional research studies, this initial evaluation is considered to be a good starting point. Continued focus into this area could be beneficial to the many men and women who have served in combat and struggle with PTSD. Additional research into this area may be able to add to the body of knowledge of how to conceptualize and better treat veterans who have experienced a stressful combat experience. 


\section{References}

Aldwin, C.W. (2007). Stress, coping, and development: An integrative approach. New York, NY: Guilford.

American Psychiatric Association. (2013). Diagnostic and Statistical Manual of Mental Disorders $\left(5^{\text {th }}\right.$ ed.). Arlington, VA: American Psychiatric Publishing.

American Psychiatric Association. (2000). Diagnostic and Statistical Manual of Mental Disorders ( $4^{\text {th }}$ ed., text rev.). Washington, DC: Author.

American Psychiatric Association. (1980). Diagnostic and statistical manual of mental disorders ( $3^{\text {rd }}$ ed.). Washington, DC: Author.

Andreasen, N.C. (2004). Brave New Brain: Conquering Mental Illness in the Era of the Genome. New York: Oxford University Press.

Barnett, V., \& Lewis, T. (1978). Outliers in statistical data. New York: Wiley.

Bollen, K. A. (1989). Structural equations with latent variables. NY: Wiley.

Bonanno, G.A., Pap, A., Lalande, K., Zhang, N., \& Noll, J.G. (2005). Grief processing and deliberate grief avoidance: A prospective comparison of bereaved spouses and parents in the United States and the People's Republic of China. Journal of Consulting and Clinical Psychology, 73, 86-98.

Buchner, A., Erdfelder, E., Faul, F., \& Lang, A. (2012). G*Power (Version 3.1.5) [Computer program]. http://www.psycho.uni-duesseldorf.de/abteilungen/aap/gpower3/

Burnell, K.J., Hunt, N., \& Coleman, P.G. (2009). Developing a model of narrative analysis to investigate the role of social support in coping with traumatic war memories. Narrative Inquiry, 19, 91-105. 
Byrne, B. M. (1994). Structural equation modeling with EQS and EQS/Windows. Thousand Oaks, CA: Sage Publications.

Calhoun, L.G. \& Tedeschi, R.G. (2006). Handbook of Posttraumatic Growth. New Jersey: Lawrence Erlbaum Associates, Inc.

Chamberlain, K., \& Zika, S. (1988). Measuring meaning in life: An examination of three scales. Personality and Individual Differences, 9, 589-596.

Creamer, M., Bell, R., \& Failla, S. (2003). Psychometric properties of the Impact of Event ScaleRevised. Behaviour Research and Therapy, 41(12), 1489-1496.

Crumbaugh, J, C. (1968). Cross-validation of Purpose-in-Life test based on Frankl's concepts. Journal of Individual Psychology, 24, 74-81.

Crumbaugh, J. C., \& Henrion, R. (1988). The PIL test: Administration, interpretation, uses, theory and critique. The International Forum for Logotherapy, 11, 76-88.

Crumbaugh, J., \& Maholick, L. (1964). An experimental study of existentialism: The psychometric approach to Frankl's concept of noogenic neurosis. Journal of Clinical Psychology, 20, 200-207.

Crumbaugh, J.C., \& Maholick, L.T. (1969). Manual of instructions for the Purpose in Life test. Abilene, TX: Viktor Frankl Institute of Logotherapy.

Crumbaugh, J, C, \& Maholick, L, T. (1981). Manual of instructions for the Purpose in Life test. Abilene, TX: Viktor Frankl Institute of Logotherapy,

Davis, C.G., Wohl, M.J.A., Verberg, N. (2007). Profiles of posttraumatic growth following an unjust loss. Death Studies, 31, 693-712. 
Department of Defense. (2011). 2011 Demographics: Profile of the Military Community.

Retrieved from http://www.militaryonesource.mil//12038/Project\%20Documents/ MilitaryHOMEFRONT/Reports/2011_Demographics_Report.pdf

Dickstein, B.D., Suvak, M. Litz, B.T., \& Adler, A.B. (2010). Heterogeneity in the course of Posttraumatic Stress Disorder: Trajectories of symptomatology. Journal of Traumatic Stress, 23, 331-339.

Elklit, A., Shevlin, M., Solomon, Z., \& Dekel, R. (2007). Factor structure and concurrent validity of the World Assumptions Scale. Journal of Traumatic Stress, 20, 291-301.

Festinger, L. (1962). Cognitive dissonance. Scientific American, 207, 93-107.

Folkman, S. (1997). Positive psychological states and coping with severe stress. Social Science \& Medicine, 45, 1207-1221.

Garmezy, N. (1973). Competence and adaptation in adult schizophrenic patients and children at risk, in Dean, S. R. (Ed.), Schizophrenia: The first ten Dean Award Lectures. NY: MSS Information Corp, pp. 163-204.

Gerber, M.M., Boals, A., \& Schuettler, D. (2011). The unique contributions of positive and negative religious coping to Posttraumatic Growth and PTSD. Psychology of Religion and Spirituality, 3, 298-307.

Guttmann, D. (1996). Logotherapy for the helping professional: Meaningful social work. New York: Springer.

Heintzelman, S.J. \& King, L.A. (2014). Life is pretty meaningful. American Psychologist, 69(6), $561-574$. 
Hoge, C.W., Castro, C.A., Messer, S.C., McGurk, D., Cotting, D.L., \& Koffman, R.L. (2004). Combat duty in Iraq and Afghanistan, mental health problems and barriers to care. New England Journal of Medicine, 351, 13-22.

Hu, L., \& Bentler, P. M. (1999). Cutoff criteria for fit indexes in covariance structure analysis: Conventional criteria versus new alternatives. Structural Equation Modeling, 6, 1-55.

Hutzell, R. R. (1989). Life Purpose Questionnaire overview sheet. Berkeley, CA: Institute of Logotherapy Press.

Janoff-Bulman, R. (1989). Assumptive worlds and the stress of traumatic events: Applications of the schema construct. Social Cognition, 7, 113-136.

Kaler, M. E., Frazier, P. A., Anders, S. L., Tashiro, T., Tomich, P., Tennen, H., \& Park, C. (2008). Assessing the psychometric properties of the World Assumptions Scale. Journal of Traumatic Stress, 21(3), 326-332.

Keller, S.M., Zoellner, L.A., \& Feeny, N.C. (2010). Understanding factors associated with early therapeutic alliance in PTSD treatment: Adherence, childhood sexual abuse history, and social support. Journal of Consulting and Clinical Psychology.

King, D. W., King, L. A., \& Vogt, D. S. (2003). Manual for the Deployment Risk and Resilience Inventory (DRRI): A Collection of Scales for Studying Deployment-Related Experiences in Military Veterans. Boston, MA: National Center for PTSD.

Kline, A., Ciccone, D. S., Weiner, M., Interian, A., Hill, L. t., Falca-Dodson, M., Black, C.M. \& Losonczy, M. (2013). Gender differences in the risk and protective factors associated with PTSD: A prospective study of National Guard troops deployed to Iraq. Psychiatry: Interpersonal and Biological Processes, 76, 256-272. 
Lee, J. A., Luxton, D. D., Reger, G. M., \& Gahm, G. A. (2010). Confirmatory factor analysis of the Posttraumatic Growth Inventory with a sample of soldiers previously deployed in support of the Iraq and Afghanistan Wars. Journal of Clinical Psychology, 66(7), 813819.

Larner, B. \& Blow, A. (2011). A model of meaning-making coping and growth in combat veterans. Review of General Psychology, 15, 187-197.

Linley, P., \& Joseph, S. (2011). Meaning in life and posttraumatic growth. Journal of Loss and Trauma, 16, 150-159.

Linley, P.A. \& Joseph, S. (2004). Postive change following trauma and adversity: A review. Journal of Traumatic Stress, 17, 11-21.

Loelin, J.C. (2004). Latent Variable Models: An Introduction to Factor, Path, and Structural Equation Analysis, Fourth Edition. New Jersey: Lawrence Erlbaum Associates.

Maguen, S., Vogt, D.S., King, L.A., King, D.W., \& Litz, B.T. (2006). Posttraumatic growth among Gulf War I veterans: The predictive roles of deployment-related experiences and background characteristics. Journal of Loss and Trauma, 11, 373-388.

MacCallum, R. C., Browne, M. W., \& Sugawara, H. M. (1996). Power analysis and determination of sample size for covariance structure modeling. Psychological Methods, 1, 130-149.

Masten, A.S. (1994). Resilience in individual development: Successful adaptation despite risk and adversity, In M. Wang \& E. Gordon (Eds.), Risk and Resilience in Inner City America: Challenges and Prospects. Hillsdale, NJ: Erlbaum.

McLean, C.P., Handa, S., Dickstein, B.D., Benson, T.A., Baker, M.T., Isler, W.C., Peterson, A.L., \& Litz, B.T., (2011). Posttraumatic growth and posttraumatic stress among military 
medical personnel. Psychological Trauma: Theory, Research, Practice, and Policy, 1, 17. doi: $10.1037 / \mathrm{a} 0022949$.

Mott, J. M., Graham, D. P., \& Teng, E. J. (2012). Perceived threat during deployment: Risk factors and relation to axis I disorders. Psychological Trauma: Theory, Research, Practice, and Policy, 4, 587-595.

Nietlisbach, G., \& Maercker, A. (2009). Social cognition and interpersonal impairments in trauma survivors with PTSD. Journal of Aggression, Maltreatment \& Trauma, 18(4), $382-402$.

Ozer, E.J., Best, S.R., Lipsey, T.L., \& Weiss, D.S. (2003). Predictors of posttraumatic stress disorder and symptoms in adults: A meta-analysis. Psychological Bulletin, 129, 52-73.

Park, C.L. (2010). Making sense of the meaning literature: An integrative review of meaning making and its effects on adjustment to stressful life events. Psychological Bulletin, 136, 257-301.

Park, C. L. (2008). Testing the meaning making model of coping with loss. Journal of Social and Clinical Psychology, 27, 970-994.

Park, C.L. (2005). Religion as a meaning-making framework in coping with life stress. Journal of social issues, 61, 707-730.

Park, C.L. \& Ai, A.L. (2006). Meaning making and growth: New directions for research on survivors of trauma. Journal of Loss and Trauma, 11, 389-407.

Park, C.L., Edmondson, D., Fenster, J.R., \& Blank, T.O. (2008). Meaning making and psychological adjustment following cancer: The mediating roles of growth, life meaning, and restored just-world beliefs. Journal of Consulting and Clinical Psychology, 76, 863875. 
Park, C. L., \& Folkman, S. (1997). Stability and change in psychosocial resources during caregiving and bereavement in partners of men with AIDS. Journal of Personality, 65, 421-447.

Parrish, I. S. (2008). "Ch. 1, Section II. HISTORY". Military Veterans PTSD Reference Manual (Revised ed.). Bryn Mawr, PA: Infinity Publishing. pp. 01-03.

Reivich, K., \& Shatte, A. (2003). The resilience factor: 7 keys to finding your inner strength and overcoming life's hurdles. New York: Broadway.

Reker, G. T. (2000). Theoretical perspective, dimensions, and measurement of existential meaning. In G. T. Reker \& K. Chamberlain (Eds.), Exploring existentialmeaning: Optimizing human development across the lifespan (pp. 39-55). Thousand Oaks, CA: Sage.

Renshaw, K. D. (2010). Deployment experiences and post-deployment PTSD symptoms in National Guard/Reserve service members serving in Operations Enduring Freedom and Iraqi Freedom. Journal of Traumatic Stress, 23, 815-818.

Resick, P., Monson, C., \& Chard, K. (2007). Cognitive Processing Therapy (CPT). US Department of Veteran Affairs.

Riviere, L. A., Kendall-Robbins, A., McGurk, D., Castro, C. A., \& Hoge, C. W. (2011). Coming home may hurt: Risk factors for mental ill health in US reservists after deployment in Iraq. The British Journal of Psychiatry, 198, 136-142.

Robak, R. W., \& Griffin, P. W. (2000). Purpose in life: What is its relationship to happiness, depression, and grieving? North American Journal of Psychology, 2,113-120.

SAS Institute Inc. (2013). Cary, NC: SAS Institute Inc. 
Schulenberg, S. E. (2004a). A psychometric investigation of logotherapy measures and the Outcome Questionnaire (OQ-45.2). North American Journal of Psychology,6, 477-492.

Scotti, J. (2014, April 17). Personal interview.

Seal, K., Metzler, T., Gima, K., Bertenthal, D., Maguen, S., \& Marmar, C. (2009). Trends and risk factors for mental health diagnoses among Iraq and Afghanistan veterans using Department of Veteran Affairs health care, 2002-2008. American Journal of Public Health, 99, 1651-1658.

Seligman, M. (2012). Flourish. New York: Simon \& Schuster.

Sharma, S., Mukherjee, S., Kumar, A., \& Dillon, W.R. (2005). A simulation study to investigate the use of cutoff values for assessing model fit in covariance structure models. Journal of Business Research, 58, 935-43.

Shay, J. (1994). Achilles in Vietnam: Combat Trauma and the Undoing of Character, Scribner, 165-66.

Shen, Y., Arkes, J., Kwan, B., Tan, L., \& Williams, T. V. (2010). Effects of Iraq/Afghanistan deployments on PTSD diagnoses for still active personnel in all four services. Military Medicine, 175, 763-769.

Sink, C. A., van Keppel, J., \& Purcell, M. (1998). Reliability estimates of the Purpose in Life and Seeking of Noetic Goals tests with rural and metropolitan area adolescents. Perceptual and Motor Skills, 86, 362.

Smith, B.W., Dalen, J., Wiggins, K. Tooley, E., Christopher, P., \& Bernard, J. (2008). The Brief Resilience Scale: Assessing the ability to bounce back. The Internal Journal of Behavioral Medicine, 15, 194-200. 
Steger, M. F., Frazier, P., Oishi, S., \& Kaler, M. (2006). The Meaning in Life Questionnaire: Assessing the presence of and search for meaning in life. Journal of Counseling Psychology, 53, 80-93.

Tabachnick, B. G. \& Fidell, L. S. (2012). Using multivariate statistics (6th ed.). London: Pearson.

Tanielian, T. (2009). Assessing combat exposure and Post-Traumatic Stress Disorder in troops and estimating the costs to society. Retrieved from http://www.rand.org/content/dam/rand/pubs/testimonies/2009/RAND_CT321.pdf.

Tanaka, J. S. (1987). How big is enough?: Sample size and goodness of fit in structural equation models with latent variables. Child Development, 58, 134-146.

Tedeschi, R.G. \& Calhoun, L.G. (1996). The Posttraumatic Growth Inventory: Measuring the positive legacy of trauma. Journal of Traumatic Stress, 9, 455-471.

Tedeschi, R.G. \& Calhoun, L.G. (2004). Posttraumatic growth: Conceptual foundations and empirical evidence. Psychological Inquiry, 15, 1-18.

Tedeschi, R.G. \& McNally, R.J. (2011). Can we facilitate Posttraumatic Growth in combat veterans? American Psychologist, 66, 19-24.

Triplett, K.N., Tedeschi, R.G., Cann, A., Calhoun, L.G., \& Reeve, C.L. (2011). Posttraumatic growth, meaning in life, and life satisfaction in response to trauma. Psychology Trauma: Theory, Research, Practice, and Policy, 1, 1-11. Doi: 10.1037/a0024204.

Vishnevsky, T., Cann, A., Caljoun, L.G., Tedeschi, R.G., Demakis, G.J. (2010). Gender differences in reported posttraumatic growth: A meta-analysis. Psychology of Women Quarterly, 34, 110-120. 
Weathers, F., Litz, B., Herman, D., Huska, J., \& Keane, T. (October 1993). The PTSD Checklist (PCL): Reliability, Validity, and Diagnostic Utility. Paper presented at the Annual Convention of the International Society for Traumatic Stress Studies, San Antonio, TX.

Weathers F., Litz B., Huska J., \& Keane T. (1994). PTSD checklist-military version. Boston: National Center for PTSD. Behavioral Sciences Division.

Werner, E. E. (1971). The children of Kauai: a longitudinal study from the prenatal period to age ten. Honolulu: University of Hawaii Press.

Wilkins, K. C., Lang, A. J., \& Norman, S. B. (2011). Synthesis of the psychometric properties of the PTSD checklist (PCL) military, civilian, and specific versions. Depression and Anxiety, 28(7), 596-606. 


\section{APPENDIX A \\ INFORMED CONSENT}

\section{Study Title: Coping in Combat Veterans}

Investigators: Jennifer Taylor, Ph.D. Rachel Spero, M.S.

WVU IRB \#: 1401173369

Please read this consent document carefully before you decide to participate in this study.

\section{Contact Persons}

In the event you experience any side effects or injury related to this research, or if you have any questions, concerns, or complaints about this research, you should contact Dr. Jennifer Taylor at (304)293-2176.

For information regarding your rights as a research subject, to discuss problems, concerns, or suggestions related to the research, to obtain information or offer input about the research, contact the Office of Research Integrity \& Compliance at (304) 293-7073.

In addition if you would like to discuss problems, concerns, have suggestions related to research, or would like to offer input about the research, contact the Office of Research Integrity and Compliance at 304-293-7073.

\section{Introduction}

You have been asked to participate in this research study, which has been explained to you by Rachel Spero. This study is being conducted by Rachel Spero in partial fulfillment of the requirements for the degree of Doctor of Philosophy in Counseling Psychology for the Department of Counseling, Rehabilitation Counseling, and Counseling Psychology at West Virginia University.

\section{Purpose(s) of the Study}

The purpose of this study is to explore the role of how veterans make meaning following a stressful life situation in combat. You will be asked questions related to the possible development of Posttraumatic Stress Disorder, posttraumatic growth, and resiliency in your own life. The researcher seeks to enroll approximately 300 veterans in this study.

\section{Who Can Be in This Study?}

1. Participants must be 18 years or older.

2. Participants must have served in combat in the U.S. Military.

If you are under 18 years of age, have not served in the military, or have not been in combat you are not eligible for participation.

\section{Description of Procedures}

This study involves completion of a survey and will take approximately 30-45 minutes for you to complete. You will be asked to fill out a questionnaire regarding your experiences after returning 
from combat. You do not have to answer all the questions. The scales will ask about thoughts and feelings you have had since returning from combat.

\section{Discomforts}

There are no expected risks from participating in this study, except for the mild frustration associated with answering the questions. Some questions may trigger anxiety for participants. Veterans that would like any mental health resources are encouraged to utilize the Veterans Crisis Line by visiting veteranscrisisline.net or calling 1-800-273-8255.

\section{Benefits}

You may not receive any direct benefit from this study. The knowledge gained from this study may eventually benefit others. Participants will add to the growing research on the different ways in which individuals cope following a stressful life event.

\section{Financial Considerations}

Participants will have the option to enter into a drawing for one of three $\$ 25$ Visa gift certificates upon completion of the study. Participants will be asked to provide their name and email address if they indicate that they are interested in being entered into the drawing. Information used for the drawing will not be linked to individual survey responses and will be used solely for the gift card drawing.

\section{Confidentiality}

All information collected for this study will be anonymous. Anonymous means that the researchers will not be collecting any information that could ever identify who you are, or link your answers to your name.

\section{Voluntary Participation}

Participation in this study is voluntary. You are free to withdraw your consent to participate in this study at any time. Refusal to participate or withdrawal will not affect you and will involve no penalty to you.

Participants are encouraged to contact the researchers at the above phone number if they have any questions. This includes, but is not limited to, requesting to see a copy of the survey questions prior to completing the survey.

\section{Please select one of the following options:}

- I have read the above information, I certify that I am at least 18 years old, and agree to be in this study. Checking this box will take me to the survey.

I I do not want to be in this study. Checking this box will take me out of the survey. 


\section{APPENDIX B \\ APPRAISED VIOLATIONS OF BELIEFS AND GOALS SCALE}

\section{Appraised Violations of Beliefs and Goals}

Park, C. L. (2008). Testing the meaning making model of coping with loss. Journal of Social and Clinical Psychology, 27(9), 970-994.

\section{Belief Violation}

When you think about how you felt before and then after being in combat, how much did the experience violate your sense of the world being fair or just?
1
2
3
4
Not At All
A Little Bit
Moderately
Very Much

When you think about how you felt before and then after being in combat, how much did the experience violate your sense that the world is a good and safe place?
1
2
3
4
Not At All
A Little Bit
Moderately
Very Much

When you think about how you felt before and then after being in combat, how much did the experience violate your sense of being in control of your life?
1
2
3
4
Not At All
A Little Bit
Moderately
Very Much

When you think about how you felt before and then after being in combat, how much did the experience violate your sense that God is in control?
1
2
3
4
Not At All
A Little Bit
Moderately
Very Much

When you think about how you felt before and then after being in combat, how much did the experience violate your sense that other forces have control in the world?
1
2
3
4
Not At All
A Little Bit
Moderately
Very Much

\section{Goal Violation}

Please rate the extent to which your combat experience has interfered with your ability to accomplish any of your life goals (e.g., companionship, social support, self-acceptance, financial security)?
1
2
3
4
Not At All
A Little Bit
Moderately
Very Much 


\section{APPENDIX C \\ THE WORLD ASSUMPTIONS SCALE}

Janoff-Bulman, R. (1989). Assumptive worlds and the stress of traumatic events: Applications of the schema construct. Social Cognition, 7, 113-136.

Please indicate the extent to which you agree with each of the following statements by using the following scale:

$1=$ strongly disagree

$2=$ disagree

$3=$ neutral

$4=$ agree

$5=$ strongly agree.

1. Misfortune is least likely to strike worthy, decent people

2. People are naturally unfriendly and unkind

3. Bad events are distributed to people at random

4. Human nature is basically good

5. Good things that happen far outnumber the bad

6. The course of our lives is largely determined by chance

7. Generally, people deserve what they get in this world

8. I often think I am no good at all

9. There is more good than evil in the world

10. I am basically a lucky person

11. People's misfortunes result from mistakes they have made

12. People don't care what happens to the next person

13. I behave in ways that maximize good results for me

14. People will experience good fortune if they are good

15. Life is too full of uncertainties that are determined by chance

16. When I think about it, I consider myself very lucky

17. I make an effort to prevent bad things from happening to mea

18. I have a low opinion of myself

19. By and large, good people get what they deserve in this world

20. We can prevent bad things from happening to us

21. I realize that chance events have worked out well for me

22. If people took preventive actions, misfortune can be avoided

23. I take actions necessary to protect myself against misfortune

24. In general, life is mostly a gamble

25. The world is a good place

26. People are basically kind and helpful

27. I usually behave so as to bring about the greatest good for me

28. I am very satisfied with the kind of person I am

29. Bad things happen, because people didn't protect themselves

30. The world is full of goodness

31. I have reason to be ashamed of my personal character

32. I am luckier than most people 
Self-Worth subscale items - 8, 10, 13, 16, 17, 18, 21, 23, 27, 28, 31, 32

Benevolence of the World subscale items - 2, 4, 5, 9, 12, 25, 26, 30

Meaningfulness of the World subscale items - 1, 3, 6, 7, 11, 14, 15, 19, 20, 22, 24, 29 


\section{APPENDIX D \\ MEANING IN LIFE QUESTIONNAIRE}

Please take a moment to think about what makes your life and existence feel important and significant to you. Please respond to the following statements as truthfully and accurately as you can, and also please remember that these are very subjective questions and there is no right or wrong answer. Please answer according to the scale below:

$\begin{array}{ccccccc}\begin{array}{c}\text { Absolutely } \\ \text { Untrue }\end{array} & \begin{array}{c}\text { Mostly } \\ \text { Untrue }\end{array} & \begin{array}{c}\text { Somewhat } \\ \text { Untrue }\end{array} & \begin{array}{c}\text { Can’t Say } \\ \text { True or } \\ \text { False }\end{array} & \begin{array}{c}\text { Somewhat } \\ \text { True }\end{array} & \begin{array}{c}\text { Mostly True } \\ \text { Absolutely } \\ \text { True }\end{array} \\ 1 & 2 & 3 & 4 & 5 & 6 & 7\end{array}$

1. ___ I understand my life's meaning.

2. ___ I am looking for something that makes my life feel meaningful.

3. I I I am always looking to find my life's purpose.

4. __ My life has a clear sense of purpose.

5. I I have a good sense of what makes my life meaningful.

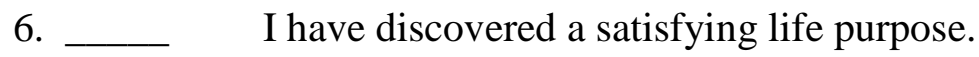

7. __ I am always searching for something that makes my life feel significant.

8. I I I am seeking a purpose or mission for my life.

9. __ My life has no clear purpose.

10. I I am searching for meaning in my life.

MLQ syntax to create Presence and Search subscales:

Presence $=1,4,5,6, \&$ 9-reverse-coded

Search $=2,3,7,8, \& 10$ 


\section{APPENDIX E \\ THE PURPOSE IN LIFE TEST \\ (Crumbaugh \& Maholick, 1964)}

Instructions: For each statement, circle the number that corresponds to what is most true for you right now.

1. I am usually:

bored

2. Life to me seems:

completely routine

12

3

4

always exciting

5

3. In life, I have:

no goals or aims

1

2
4

clear goals and aims

5 enthusiastic

5

4. My personal existence is:

utterly meaningless,

without purpose

12

3

4

5. Every day is:

exactly the same

12

3

4

constantly new and different 5

6. If I could choose, I would:

prefer never to have

want 9 more lives just like this one

been born

1

2

3

4

5

7. After retiring, I would:

loaf completely

the rest of my life

12

3

4

do some of the exciting things I've always wanted to do

5

8. In achieving life goals, I've:

made no progress

whatever

1

2

3

4

progressed to complete fulfillment

5 
9. My life is:

empty, filled only

running over with exciting things

with despair

12

34

5

10. If I should die today, I'd feel that my life has been: completely worthless

12

11. In thinking of my life, I:

often wonder why

I exist

1

2 very worthwhile

5

always see reasons for being here

5

12. As I view the world in relation to my life, the world: completely confuses me

1 2 3

4

fits meaningfully with my life

13. I am a:

very irresponsible person 1 2 3

4

very responsible person

5

14. Concerning freedom to choose, I believe humans are: completely bound by limitations of heredity and environment 1 2 3

4 5

15. With regard to death, I am:

Unprepared prepared and unafraid And frightened 1 2 3 4

16. Regarding suicide, I have: thought of it seriously as a way out 1 2 3

totally free to make all life choices

\section{5}

never given it a second thought 
17. I regard my ability to find a purpose or mission in life as: practically none

12

3

4

very great

2

18. My life is:

out of my hands and

controlled by external

in my hands and I'm in control of it

factors

1

2

3

4

5

19. Facing my daily tasks is:

a painful and

a source of pleasure and satisfaction

boring experience

12

3

4

5

20. I have discovered:

no mission or

purpose in life

12

23

34

a satisfying life purpose

5

Scoring: Add up all the scores you circled and write the total here 


\section{APPENDIX F \\ FINDING/FOUND MEANING QUESTIONS}

\section{Finding Meaning}

How much have you been trying to make sense of or find any meaning in your experience?

1

Not At All
2

A Little Bit
3

Moderately
4

Very Much

\section{Found Meaning}

Do you believe that you have been able to make sense of or find any meaning in your experience?

$\begin{array}{lccc}1 & 2 & 3 & 4 \\ \text { Not At All } & \text { A Little Bit } & \text { Moderately } & \text { Very Much }\end{array}$




\section{APPENDIX G \\ IMPACT OF EVENTS SCALE- REVISED}

INSTRUCTIONS: Below is a list of difficulties people sometimes have after stressful life events. Please read each item, and then indicate how distressing each difficulty has been for you DURING THE PAST SEVEN DAYS with respect to your time in combat. How much were you distressed or bothered by these difficulties?

$0=$ Not at all

$1=$ A little bit

$2=$ Moderately

$3=$ Quite a bit

$4=$ Extremely

1. Any reminder brought back feelings about it.

2. I had trouble staying asleep.

3. Other things kept making me think about it.

4. I felt irritable and angry.

5. I avoided letting myself get upset when I thought about it or was reminded of it.

6. I thought about it when I didn't mean to.

7. I felt as if it hadn't happened or wasn't real.

8. I stayed away from reminders of it.

9. Pictures about it popped into my mind.

10. I was jumpy and easily startled.

11. I tried not to think about it.

12. I was aware that I still had a lot of feelings about it, but I didn't deal with them.

13. My feelings about it were kind of numb.

14. I found myself acting or feeling like I was back at that time.

15. I had trouble falling asleep.

16. I had waves of strong feelings about it.

17. I tried to remove it from my memory.

18. I had trouble concentrating.

19. Reminders of it caused me to have physical reactions, such as sweating, trouble breathing, nausea, or a pounding heart.

20. I had dreams about it.

21. I felt watchful and on-guard.

22. I tried not to talk about it.

Total IES-R score:

The Intrusion subscale is the MEAN item response of items 1, 2, 3, 6, 9, 14, 16, 20. Thus, scores can range from 0 through 4.

The Avoidance subscale is the MEAN item response of items 5, 7, 8, 11, 12, 13, 17, 22. Thus, scores can range from 0 through 4 .

The Hyperarousal subscale is the MEAN item response of items 4, 10, 15, 18, 19, 21. Thus, scores can range from 0 through 4 . 


\section{APPENDIX H \\ PTSD-CHECKLIST (MILITARY/5)}

Below is a list of problems and complaints that veterans sometimes have in response to a stressful military experience. Please read each one carefully, put an " $\mathrm{X}$ " in the box.

\begin{tabular}{|c|c|c|c|c|c|}
\hline \multirow{2}{*}{\multicolumn{6}{|c|}{$\begin{array}{l}\text { 1. Repeated, disturbing } \\
\text { memories, thoughts, or } \\
\text { images of a stressful } \\
\text { military experience? }\end{array}$}} \\
\hline & & & & & \\
\hline \multicolumn{6}{|l|}{$\begin{array}{l}\text { 2. Repeated, disturbing } \\
\text { dreams of a stressful } \\
\text { military experience? }\end{array}$} \\
\hline \multicolumn{6}{|l|}{$\begin{array}{l}\text { 3. Suddenly acting or } \\
\text { feeling as if a stressful } \\
\text { military experience were } \\
\text { happening again (as if you } \\
\text { were reliving it)? }\end{array}$} \\
\hline \multicolumn{6}{|l|}{$\begin{array}{l}\text { 4. Feeling very upset when } \\
\text { something reminded you of } \\
\text { a stressful military } \\
\text { experience? }\end{array}$} \\
\hline \multicolumn{6}{|l|}{$\begin{array}{l}\text { 5. Having physical reactions } \\
\text { (e.g., heart pounding, } \\
\text { trouble breathing, or } \\
\text { sweating) when something } \\
\text { reminded you of a stressful } \\
\text { military experience? }\end{array}$} \\
\hline \multicolumn{6}{|l|}{$\begin{array}{l}\text { 6. Avoid thinking about or } \\
\text { talking about a stressful } \\
\text { military experience or avoid } \\
\text { having feelings related to it? }\end{array}$} \\
\hline \multicolumn{6}{|l|}{$\begin{array}{l}\text { 7. Avoid activities or talking } \\
\text { about a stressful military } \\
\text { experience or avoid having } \\
\text { feelings related to it? }\end{array}$} \\
\hline \multicolumn{6}{|l|}{$\begin{array}{l}\text { 8. Trouble remembering } \\
\text { important parts of a stressful } \\
\text { military experience? }\end{array}$} \\
\hline \multicolumn{6}{|l|}{$\begin{array}{l}\text { 9. Loss of interest in things } \\
\text { that you used to enjoy? }\end{array}$} \\
\hline \multicolumn{6}{|l|}{$\begin{array}{l}\text { 10. Feeling distant or cut off } \\
\text { from other people? }\end{array}$} \\
\hline $\begin{array}{l}\text { 11. Feeling emotionally } \\
\text { numb or being unable to }\end{array}$ & & & & & \\
\hline
\end{tabular}




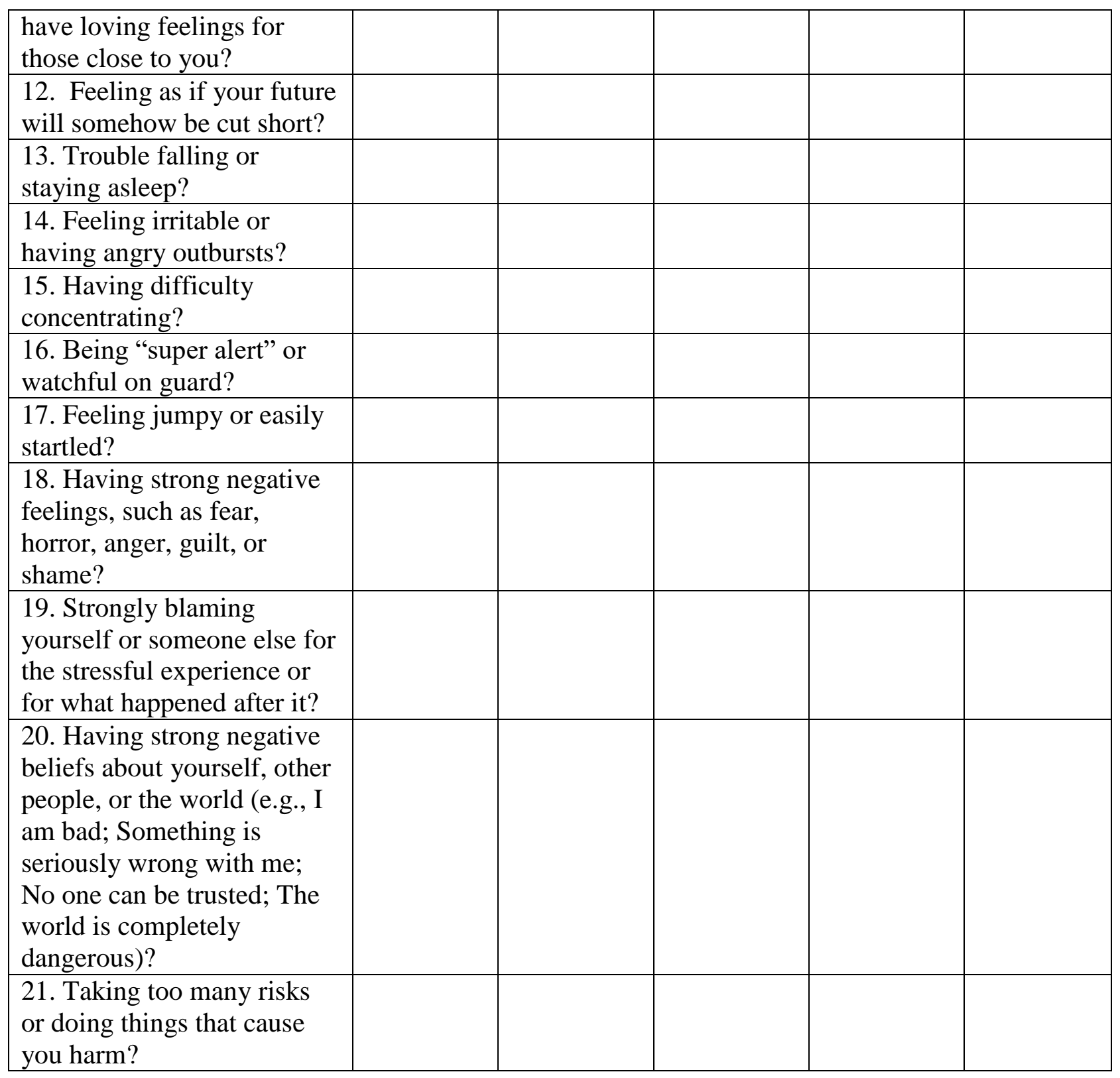

Has anyone indicated that you've changed since the stressful military experience? Yes No 


\section{APPENDIX I \\ THE BRIEF RESILIENCE SCALE}

Smith, B.W., Dalen, J., Wiggins, K., Tooley, E., Christopher, P., \& Bernard, J. (2008). The Brief Resilience Scale: Assessing the ability to bounce back. The International Journal of Behavioral Medicine, 15, 194-200.

Please indicate the extent to which you agree with each of the following statements by using the following scale:

$1=$ strongly disagree

$2=$ disagree

$3=$ neutral

$4=$ agree

$5=$ strongly agree.

1. I tend to bounce back quickly after hard times

2. I have a hard time making it through stressful events (R)

3. It does not take me long to recover from a stressful event

4. It is hard for me to snap back when something bad happens $(\mathrm{R})$

5. I usually come through difficult times with little trouble

6. I tend to take a long time to get over set-backs in my life (R) 


\section{APPENDIX J \\ POSTTRAUMATIC GROWTH INVENTORY}

Tedeschi R.G. \& Calhoun L.G. (1996). The Posttraumatic Growth Inventory: Measuring the positive legacy of trauma. Journal of Traumatic Stress, 9, 455-471.

Indicate for each of the statements below the degree to which this change occurred in your life as a result of being in combat, using the following scale.

$0=$ I did not experience this change

$1=\mathrm{I}$ experienced this change to a very small degree

$2=$ I experienced this change to a small degree

$3=$ I experienced this change to a moderate degree

$4=$ I experienced this change to a great degree

$5=\mathrm{I}$ experienced this change to a very great degree

1. My priorities about what is important in life.

2. An appreciation for the value of my own life.

3. I developed new interests.

4. A feeling of self-reliance.

5. A better understanding of spiritual matters.

6. Knowing that I can count on people in times of trouble.

7. I established a new path for my life.

8. A sense of closeness with others.

9. A willingness to express my emotions,

10. Knowing I can handle difficulties.

11. I'm able to do better things with my life.

12. Being able to accept the way things work out.

13. Appreciating each day.

14. New opportunities are available which wouldn't have been otherwise.

15. Having compassion for others.

16. Putting effort into my relationships.

17. I'm more likely to try to change things which need changing.

18. I have a stronger religious faith.

19. I discovered that I'm stronger than I thought I was.

20. I learned a great deal about how wonderful people are.

21. I accept needing others. 


\section{APPENDIX K COMBAT EXPOSURE SCALE}

The statements below describe the types of things that military personnel experience during combat, or while stationed in or near an area of conflict. These include all experiences that occur on land, in the air, or at sea. Some of the questions also apply to non-combat situations.

Read each statement and indicate if it did ("Yes") or did not ("No") happen to you.

\begin{tabular}{|c|c|c|}
\hline \multirow{2}{*}{ I was stationed in a conflict area and under threat of enemy fire } & No & Yes \\
\hline & & \\
\hline $\begin{array}{l}\text { I went on dangerous duties, such as combat patrols, sorties, convoys, and } \\
\text { route and mine clearance }\end{array}$ & & \\
\hline I encountered land or water mines, booby traps, or IEDs & & \\
\hline $\begin{array}{l}\text { I came under incoming fire from enemy forces (e.g., rifles, grenades, } \\
\text { mortars, artillery, rockets, bombs, missiles, torpedoes) }\end{array}$ & & \\
\hline $\begin{array}{l}\text { I came under incoming fire from friendly forces (e.g., rifles, grenades, } \\
\text { mortars, artillery, rockets, bombs, missiles, torpedoes) }\end{array}$ & & \\
\hline $\begin{array}{l}\text { I fired my weapons at the enemy forces (e.g., rifles, grenades, mortars, } \\
\text { artillery, rockets, bombs, missiles, torpedoes) }\end{array}$ & & \\
\hline I was part of an amphibious assault or naval invasion & & \\
\hline My unit suffered causalities (e.g., captured, wounded, killed) & & \\
\hline $\begin{array}{l}\text { I saw someone from the allied forces being wounded or killed by incoming } \\
\text { or outgoing fire }\end{array}$ & & \\
\hline $\begin{array}{l}\text { I saw someone from the enemy forces being wounded or killed by incoming } \\
\text { or outgoing fire }\end{array}$ & & \\
\hline I saw a civilian being wounded or killed by incoming or outgoing fire & & \\
\hline I killed or I think I killed someone in combat & & \\
\hline $\begin{array}{l}\text { I saw the bodies of people who had been killed (e.g., allied forces, civilians, } \\
\text { enemy forces) }\end{array}$ & & \\
\hline $\begin{array}{l}\text { I handled the bodies of people who had been killed (e.g., allied forces, } \\
\text { civilians, enemy forces) }\end{array}$ & & \\
\hline I defused an explosive device (e.g., booby trap, mine, bomb, IED) & & \\
\hline I saw homes and villages that had been destroyed & & \\
\hline I thought that I would be wounded or killed & & \\
\hline $\begin{array}{l}\text { I saw children being wounded or killed, or saw the bodies of children who } \\
\text { had been killed }\end{array}$ & & \\
\hline
\end{tabular}




\section{APPENDIX L DEMOGRAPHICS FORM}

1. What is your age?

2. Gender:
Male
Female
Other
Please specify:

3. What state do you currently live in:

[Drop down menu of all 50 states and the U.S. territories of Puerto Rico, Guam, and the Virgin Islands]

4. Please specify your ethnicity:

$\square$ White

$\square$ Hispanic or Latino

Black or African American

$\square$ Native American or American Indian

$\square$ Asian / Pacific Islander

$\square$ Other

5. How many deployments have you had:

6. What was the length of each deployment:

7. What was the location of your deployment (select all that apply):

Iraq

Afghanistan

Kuwait

Kosovo

Saudi Arabia

Uzbekistan

Surrounding Middle Eastern State (please specify)

Other Conflict Zone (please specify) 
8. What is your highest level of education:

\section{GED}

High school diploma

Some college

Associate's Degree

Bachelor's Degree

Some graduate school

Master's Degree

Doctoral Degree

9. Which branch of the military are you/were you in:

\section{Air Force}

Army

Marines

Navy

Coast Guard

10. What is your military grade: (survey will have a drop-down menu that will have the following choices)

E-1, E-2, E-3, E-4, E-5, E-6, E-7, E-8, E-9, W-1, W-2, W-3, W-4, W-5, O-1, O-2, O-3, O-4, O-5, O-6, O-7 through O-10 (for de-identification purposes these small groups have been condensed)

11. What would you consider your current income level:

Below the Poverty Line

Lower Class/Poor

Lower Middle Class

Middle Class

Upper Middle Class

Upper Class

12. How religious or spiritual do you consider yourself?

1

Not religious

or spiritual at all
$2-3$

3
4 Very religious or spiritual

13. While you were deployed were you ever exposed to a blast or did you sustain a head injury in which you lost consciousness or became confused afterwards?

$\square$ Yes
$\square \quad$ No 
14. While you were deployed, did you sustain an injury that has led to a permanent physical disability or chronic pain?

Yes

$\square$ No

15. How supportive do you believe your friends have been since you have returned home from combat?

$\begin{array}{lllcc}1 & 2 & 3 & 4 & 5 \\ \text { Not supportive at all } & & & \text { Very supportive }\end{array}$

16. How supportive do you believe your family has been since you have returned home from combat?

$\begin{array}{lllcc}1 & 2 & 3 & 4 & 5 \\ \text { Not supportive at all } & & & \text { Very supportive }\end{array}$

17. Have you received any mental health treatment since you have returned from combat?

$\square$ Yes

$\square$ No

18. If yes, what was the reason for the treatment (check all that may apply)

Readjustment Issues

PTSD

Depression

Suicide

Anxiety

Bipolar Disorder

Schizophrenia

Other

Please Specify: 